UNIVERSIDADE DE SÃO PAULO

HOSPITAL DE REABILITAÇÃO DE ANOMALIAS CRANIOFACIAIS

THIAGO FREIRE LIMA

ANÁLISE TRIDIMENSIONAL DAS VIAS AÉREAS SUPERIORES DE PACIENTES COM FISSURA LABIOPALATINA E DISCREPÂNCIA MAXILOMANDIBULAR 



\title{
ANÁLISE TRIDIMENSIONAL DAS VIAS AÉREAS SUPERIORES DE PACIENTES COM FISSURA LABIOPALATINA E DISCREPÂNCIA MAXILOMANDIBULAR
}

\author{
Dissertação apresentada ao Hospital de Reabilitação \\ de Anomalias Craniofaciais da Universidade de São \\ Paulo para obtenção do título de Mestre em Ciências \\ da Reabilitação. \\ Área de concentração: Fissuras Orofaciais e \\ Anomalias Relacionadas \\ Orientadora: Profa. Dra. Ivy Kiemle Trindade \\ Suedam
}




\section{UNIVERSIDADE DE SÃO PAULO \\ HOSPITAL DE REABILITAÇÃO DE ANOMALIAS CRANIOFACIAIS}

R. Silvio Marchione, 3-20

Caixa Postal: 1501

17012-900 - Bauru - SP - Brasil

Telefone: (14) 3235-8000

Prof. Dr. Marco Antonio Zago $\quad$ - Reitor da USP

Dra. Regina Célia Bortoleto Amantini - Superintendente do HRAC -USP

Autorizo, exclusivamente, para fins acadêmicos e científicos, a

reprodução total ou parcial desta Tese.

Nome/assinatura

Bauru de de

Lima, Thiago Freire

L628a Análise tridimensional das vias aéreas superiores de pacientes com fissura labiopalatina e discrepância maxilomandibular / Thiago Freire Lima. Bauru, 2015.

89p.; il.; $30 \mathrm{~cm}$.

Dissertação (Mestrado - Área de Concentração: Fissuras Orofaciais e Anomalias Relacionadas) - Hospital de Reabilitação de Anomalias Craniofaciais, Universidade de São Paulo.

Orientadora Profa. Dra. Ivy Kiemle Trindade Suedam

1.Fissura Palatina 2. Faringe 3. Tomografia Computadorizada de Feixe Cônico 


\section{FOLHA DE APROVAÇÃO}

\section{Thiago Freire Lima}

Dissertação apresentada ao Hospital de Reabilitação de Anomalias Craniofaciais da Universidade de São Paulo para a obtenção do título de Mestre.

Área de Concentração: Fissuras Orofaciais e Anomalias Relacionadas

Aprovado em:

Banca Examinadora

Prof. Dr.

Instituição

Prof. Dr.

Instituição

Profa Dra. Ivy Kiemle Trindade Suedam - Orientadora

Faculdade de Odontologia de Bauru - FOB-USP

Hospital de Reabilitação de Anomalias Craniofaciais - HRAC-USP

Profa. Dra. Daniela Gamba Garib Carreira

Presidente da Comissão de Pós-Graduação do HRAC-USP

Data de depósito da dissertação junto à SPG: 



\section{THIAGO FREIRE LIMA}

21 de outubro de 1988 Presidente Epitácio/SP

2007-2010

2010-2011

2011

2012

2012-2014

2012-2014

2013 até a presente data
Nascimento

Graduação em Odontologia pela Faculdade de Odontologia de Bauru Universidad de São Paulo (FOB/USP)

Aperfeiçoamento em Cirurgia Periodontal - APCD - Bauru,SP.

Aperfeiçoamento em Periodontia IEO - Bauru,SP.

Aperfeiçoamento em Implantodontia - IOCP - Bauru,SP.

Especialização de Cirurgia e Traumatologia Buco-Maxilo-Facial. USC - Bauru, SP.

Especialização em Implantodontia P-I Branemark Institute - Bauru, SP.

Mestrado em Ciências da Reabilitação. Área de concentração: Fissuras Orofaciais e Anomalias Relacionadas - Hospital de Reabilitação de Anomalias Craniofaciais da Universidade de São Paulo (HRAC - USP). 



\section{DEDICATÓRIA}

Dedico este trabalho à minha famítia, aos os colegas da turma de mestrado especialmente, e à todos aqueles que de uma maneira ou de outra se fizeram presentes nesta minha conquista. 



\section{AGRADECIMENTOS}

Agradeço primeiramente ao Pai Celestial por iluminar mew caminho, sendo minha fonte de luz e força para enfrentar os momentos de dificuldades que encontramos ao longo da trajetóría da vida sabedoria e paciência.

Agradeço em especial a minha orientadora Profa. Ivy, pelo conhecimento compartithado, pela paciéncia e dedicação na minha formação, peto sew exemplo de profissionalismo, competência, dedicação e pela confiança em mim depositada e pelas oportunidades profissionais concedidas, fazendo com que o sonho do intercâmbio acadêmico se tornasse realidade

Ao Prof. Luiz Pimenta, pessoa pela qual agradeço todos os funcionários e colegas da UNC-Chapel Hill - USA, pelo conhecimento compartithado e por fazerem $\sigma$ dia a día no outro continente se parecesse mais familiar.

Á todos os professores e mestres que fizeram parte de todos os niveis de aprendizado anteriormente realizados. Em especial aos professores da residência em CTBMF e da especialização de Implantodontia; são eles: Dr. Paulo Domingos, Dr. Padovan, Dr. Hugo Nary e Dr. Gümar Batista (in memoriam). Pessoas que contribuiram para engrandecer mew conhecimento e de forma direta ou indiretamente fizeram com que eu pudesse aproveitar o mestrado com outra visão. 

Ao Dr. Reinaldo Mazzottini e ao Dr. José Carlos da Cunha Bastos Jr, pela amizade e ensinamentos.

À equipe de professores e profissionais da fisiologia pela ótima convivência, paciência e conhecimentos compartithados.

Aos funcionários da pós graduação do HRAC, pessoas que tenho imenso apreço, que nunca mediram esforços em nos ajudar, viabilizando a parte burocrática. dos nossos sonhos.

À FAPESP por financiar o nosso trabalho bem como mew estágio em pesquisa no exterior. E ao Prof. Carlos Ferreira dos Santos pela disponibilidade em ajudar e orientar $\sigma$ desenvolvimento dessa parcería.

A Camila Libardi, que mesmo quando distante, sempre se fez presente, fazendo com que o mew dia-a-dia se tornasse mais agradável, principalmente nos momentos de díficuldades.

Aos colegas do Pitangueiras, Abbas, Tanga, Paçoca, Valtinho, Wilson, Axpíra, Caio e Mônica, pelos momentos de descontração, compartithamento de conhecimentos e experiencias profissionais e acadêmicas. compartithadas.

À todos aqueles que fizeram parte da minha rotina durante este período de pós graduação, deixo mens mais sinceros e cordiais agradecimentos... 



\section{RESUMO}

Lima TF. Análise tridimensional das vias aéreas superiores de pacientes com fissura labiopalatina e discrepância maxilomandibular [dissertação]. Bauru: Hospital de Reabilitação de Anomalias Craniofaciais, Universidade de São Paulo; 2015.

Objetivos: As fissuras labiopalatinas constituem a malformação congênita de maior prevalência na espécie humana. $O$ fechamento cirúrgico do lábio e do palato, que visa restaurar a forma e a função, paradoxalmente impacta negativamente sobre o crescimento maxilar e, consequentemente, sobre a morfofisiologia nasal, levando à deformidades como desvio de septo e hipertrofia das conchas nasais. Estas alterações reduzem as dimensões internas da cavidade nasal e aumentam a resistência ao fluxo aéreo respiratório. Assim, foi objetivo do presente estudo avaliar tridimensionalmente o espaço aéreo faríngeo dos pacientes com fissura labiopalatina unilateral completa por meio de tomografia computadorizada de feixe cônico. Material e Métodos: Foram avaliados exames tomográficos de dois grupos de pacientes: 1) Grupo Controle (GC): 30 tomografias de pacientes sem FLP + discrepância maxilomandibular do tipo classe III de Angle, e, 2) Grupo Fissura (GF): 30 tomografias de pacientes com FLP unilateral completa + discrepância maxilomandibular do tipo classe III de Angle. Dois avaliadores treinados e calibrados avaliaram, em dois tempos distintos, as imagens por meio do software Dolphin Imaging 11.0, no qual foram obtidos valores de volume (V) faríngeo e da área seccional mínima faríngea (ASM). Os valores médios da ASM e do V, obtidos nas duas medições do avaliador 1 , foram considerados para análise. A reprodutibilidade intra e interexaminador foram calculadas pelo Coeficiente de Correlação Intraclasse. A significância das diferenças entre os grupos foram avaliadas pelo teste " $t$ " de Student para amostras independentes. A correlação entre as variáveis foi aferida pelo Coeficiente de correlação de Pearson. Valores de $p<0.05$ foram considerados significantes. Resultados: Os valores médios de $V\left(\mathrm{~mm}^{3}\right)$ do $\mathrm{GF}(20,9 \pm 5,0)$ foram significantemente menores que os do GC $(26,9 \pm 9,6) \quad(p=0,004)$. Apesar de estatisticamente não significante, os indivíduos do GF apresentam as ASMs dimensionalmente menores $(158,6 \pm 99,1)$ que as do $G C(188,8 \pm 110,2)$. Constatou-se forte correlação positiva entre as variáveis ASM e V, nos grupos GC e GF $(p<0.001)$ e forte correlação negativa entre as variáveis ASM e idade, apenas no grupo GF $(p=0.017)$. Conclusão: $A$ faringe do paciente com fissura labiopalatina unilateral completa com discrepância dento-esquelética classe III de Angle é volumetricamente menor que a de indivíduos sem fissura labiopalatina com o mesmo tipo de discrepância dento-esquelética. Este resultado sugere maior chance de colapsabilidade da faringe, e, consequentemente, maior risco para apneia obstrutiva do sono nesta população.

Palavras chaves: Fissura palatina, faringe, tomografia computadorizada de feixe cônico. 



\begin{abstract}
Lima TF. Three-dimensional analysis of the upper airways of patients with cleft palate and maxillomandibular discrepancy [dissertation]. Bauru: Hospital de Reabilitação de Anomalias Craniofaciais, Universidade de São Paulo; 2015.

Objective: Cleft lip and palate (CLP) is the most prevalent congenital malformation in humans. Primary plastic surgeries, which main objective is to repair the anatomy and the function of the lip and palate, paradoxically, impair maxillary growth and, consequently, impact negatively on the nasal morphophysiology, leading to deformities such as septal deviation and turbinate hypertrophy. These changes reduce the internal nasal dimensions and increase the resistance to respiratory airflow. The aim of the present study was to evaluate three-dimensionally the pharyngeal airway space of individuals with complete unilateral cleft lip and palate by means of cone beam computed tomography. Materials and Methods: Two groups were evaluated: 1) Control group ( $\mathrm{CoG}$ ): $30 \mathrm{CT}$ scans of individuals without CLP + Angle class III malocclusion, and 2) Cleft group (CIG): $30 \mathrm{CT}$ scans of individuals with CLP + Angle class III malocclusion. Two trained and calibrated examiners assessed the images, in two different moments, by means of Dolphin Imaging 11.0 software. Mean values of pharyngeal volumes $(V)$ and minimal cross-sectional areas (CSA) obtained by examiner 1 were considered for analysis. Intra and inter-examiner reproducibility were assessed by Intraclass correlation coeficiente test. The significance of differences between groups was evaluated by Student " $t$ " test for independent samples. The correlation between variables was assessed using Pearson's correlation coefficient. $P$ values $<0.05$ were considered significant. Results: Mean values of $\mathrm{V}\left(\mathrm{mm}^{3}\right)$ for the CIG $(20,9 \pm 5,0)$ were significantly lower than for the CoG $(26,9 \pm 9,6)(p=0,004)$. Although not statistically significant, individuals from the CIG presented with lower ASMs $(158,6 \pm 99,1)$ than the CG individuals $(188.8 \pm 110,2)$. A strong positive correlation was observed between the ASM and V variables in both groups $(p<0.001)$ and a strong negative correlation was observed between the variables ASM and age, only for the CIG ( $p=0.017)$. Conclusion: The pharynx of the patients with complete unilateral cleft lip and palate and with Angle Class III malocclusion is volumetrically smaller than that of individuals without cleft lip and palate and with the same type of skeletal discrepancy. This result suggests a greater chance for pharyngeal collapsibility in individuals with cleft lip and palate and, consequently, a greater risk for obstructive sleep apnea in this population.
\end{abstract}

Keywords: Cleft palate, pharynx, cone beam computed tomography . 



\section{LISTA DE QUADROS E FIGURAS}

Quadro 1 - Classificação das fissuras, segundo Spina et al (1972) e modificada por Silva Filho et al (1992), e adotada no HRAC-USP

Figura 1 - Diagrama representativo da classificação das fissuras de acordo com as modificações propostas por Silva Filho OG, Freitas JAS, 2007 In: Trindade IEK, Silva Filho OG. Fissuras labiopalatinas: uma abordagem interdisciplinar

Figura 2 - Tipos de fissuras: Pré-forame incisivo (2A e 2B); transforame incisivo unilateral $(2 \mathrm{C}$ e $2 \mathrm{D})$; transforame incisivo bilateral (2E e $2 \mathrm{~F}$ ); pós-forame incisivo (2G); fissura rara da face $(2 \mathrm{H})$. 18

Figura 3 - Vista frontal (3A) e perfil (3B) de paciente adulto com fissura transforame incisivo unilateral esquerda não operada. Notar perfil normal. Vista frontal (3C) e perfil (3D) de paciente adulto com fissura transforame incisivo bilateral operada. Notar retrusão nasomaxilar resultando em perfil côncavo

Figura 4 - Tela do programa Dolphin Imaging 11.0 que mostra o corte sagital mediano, à esquerda, e a marcação dos pontos anatômicos: Ba (Básio), S '(ponto mais anterosuperior da sela pituitária), C4 (limite anteroinferior da $4^{\mathrm{a}}$ vértebra cervical) e $\mathrm{H}$ (limite anteroinferior do osso hióide) para obtenção do polígono que delimita a área faríngea; ...

Figura 5 - Tela do programa Dolphin Imaging 11.0 que mostra à esquerda: marcação do espaço aéreo e coloração da área de interesse faríngea; à direita: reformatação do volume (visão tridimensional) e obtenção dos valores numéricos, expressos em $\mathrm{mm}^{3}$; e determinação da área seccional mínima, expressa em $\mathrm{mm}^{2}$, que representa a área de maior constrição da faringe .

Figura 6 - Valores médios das áreas seccionais mínimas (ASM) faríngeas, expressos em $\mathrm{mm}^{2}$, do grupo controle (GC) e do grupo fissura (GF), aferidos por tomografia computadorizada de feixe cônico. 

Figura 7 - Valores médios dos volumes (V) faríngeos, expressos em $\mathrm{cm}^{3}$, do grupo controle (GC) e do grupo fissura (GF), aferidos por tomografia computadorizada de feixe cônico. $O$ asterisco índia diferença estatisticamente significante entre os grupos (GC vs GF).

Figura 8 - Imagens tridimensionais da área seccional mínima (ASM) e dos volumes faríngeos. A primeira de um indivíduo do grupo controle (GC) e a segunda de um indivíduo do grupo com fissura (GF)

Figura 9 - Gráfico de correlação das variáveis ASM e V, no grupo GC.

Figura 10 - Gráfico de correlação das variáveis $A S M$ e V, no grupo GF 58

Figura 11 - Gráfico de correlação das variáveis ASM e idade, no grupo GF 



\section{LISTA DE TABELAS}

Tabela 1 - Valores do Coeficiente de Correlação Intraclasse (ICC) (Fleiss JL 1999) das medidas da área seccional mínima (ASM) e do volume (V) médios do avaliador 1, nos tempos T1 e T2, para os grupos controle (GC) e com fissura(GF) e entre os avaliadores 1 e 2

Tabela 2 - Valores individuais de duas medições (T1 e T2) realizadas pelos avaliadores 1 e 2 e valores médios das áreas seccionais mínimas (ASM) faríngeas, expressos em $\mathrm{mm}^{2}$, do grupo controle $(\mathrm{GC}=30$ indivíduos sem fissura labiopalatina), aferidos por tomografia computadorizada de feixe cônico

Tabela 3 - Valores individuais de duas medições (T1 e T2) realizadas pelos avaliadores 1 e 2 e valores médios das áreas seccionais mínimas (ASM) faríngeas, expressos em $\mathrm{mm}^{2}$, do grupo fissura (GF $=30$ indivíduos com fissura labiopalatina), aferidos por tomografia computadorizada de feixe cônico

Tabela 4 - Valores individuais de duas medições (T1 e T2) realizadas pelos avaliadores 1 e 2 e valores médios dos volumes $(V)$ faríngeos, expressos $\mathrm{em} \mathrm{cm}^{3}$, do grupo controle $(\mathrm{GC}=30$ indivíduos sem fissura labiopalatina), aferidos por tomografia computadorizada de feixe cônico

Tabela 5 - Valores individuais de duas medições (T1 e T2) realizadas pelos avaliadores 1 e 2 e valores médios dos volumes $(V)$ faríngeos, expressos $\mathrm{em} \mathrm{cm}^{3}$, do grupo fissura ( $G F=30$ indivíduos com fissura labiopalatina), aferidos por tomografia computadorizada de feixe cônico

Tabela 6 - Valores médios das áreas seccionais mínimas (ASM) e dos volumes $(V)$ faríngeos, expressos em $\mathrm{mm}^{2} \mathrm{e} \mathrm{cm}^{3}$, respectivamente, do grupo controle (GC) e do grupo fissura (GF), aferidos por tomografia computadorizada de feixe cônico 



\section{SUMÁRIO}

1 INTRODUÇÃO E REVISÃO DE LITERATURA 11

1.1 Considerações sobre as fissuras labiopalatinas 13

1.2 Considerações sobre o protocolo reabilitador do indivíduo com fissura labiopalatina.....

1.3 Considerações sobre as vias aéreas superiores de indivíduos com fissura labiopalatina .

1.4 Considerações sobre a tomografia computadorizada de feixe cônico e aferição tridimensional das vias aéreas superiores.

2 OBJETIVOS

$3 \quad$ MATERIAL E MÉTODOS

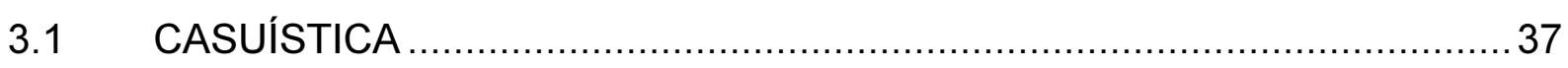

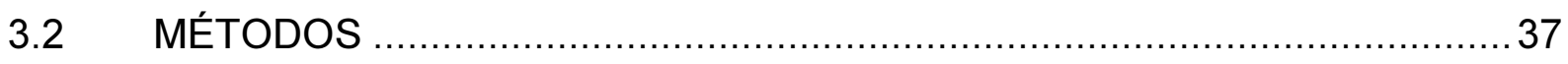

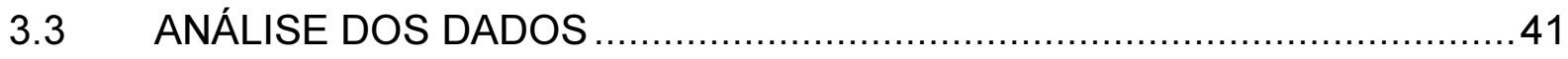

$4 \quad$ RESULTADOS

4.1 ÁREAS SECCIONAIS MÍNIMAS FARÍNGEAS …................................. 45

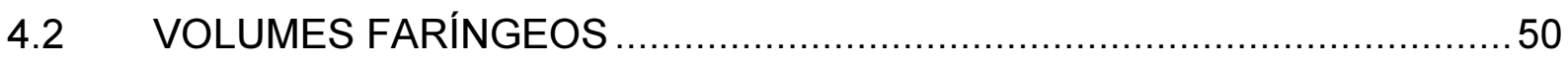

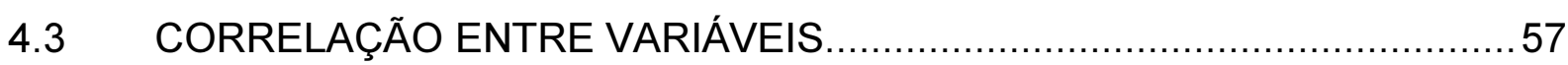

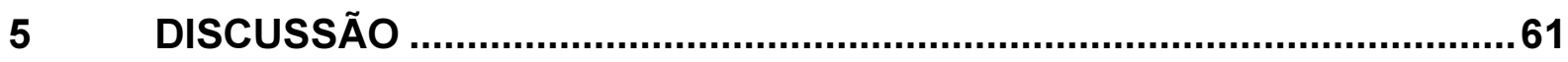

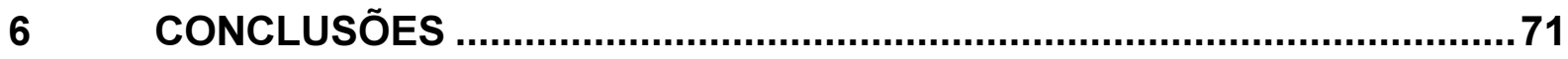

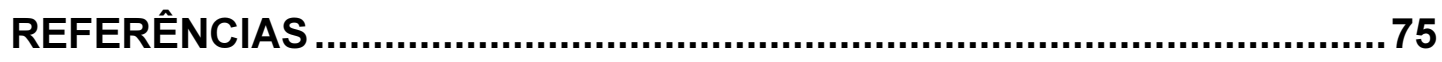

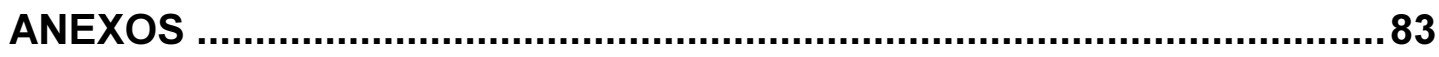





\section{INTRODUÇÃO E REVISÃO DE LITERATURA}





\section{INTRODUÇÃO E REVISÃO DE LITERATURA}

\subsection{Considerações sobre as fissuras labiopalatinas}

Denomina-se fissura, em patologia, o quadro clínico no qual ocorre uma descontinuidade anatômica dos tecidos mole, duro ou ambos. Quando acomete o complexo maxilofacial, a fissura pode envolver, individualmente ou em concomitância, o lábio superior, o processo ósseo alveolar superior e o palato. É uma das malformações congênitas de maior prevalência na espécie humana. As fissuras de lábio, com o envolvimento ou não do processo alveolar e do palato, ocorrem em, aproximadamente, 2:1000 indivíduos na raça amarela, 1:1000 indivíduos na raça branca e 0,3:1000 indivíduos na raça negra. (Gorlin, Cohen Jr e Levin 1990). No Brasil, admite-se que a incidência de fissuras labiopalatinas oscila em torno de 1:650 nascimentos (Nagem-Filho, Morais e Rocha 1968).

O mecanismo embriológico causador de uma fissura de lábio e de palato primário se dá entre a quinta (Cate 2001) e a oitava (Diewert 1983 e Sperber 1989) semana de desenvolvimento do embrião, quando ocorre uma falha na fusão da face lateral dos processos nasais mediais com a extensão anterior dos processos maxilares de cada lado e dos processos nasais mediais entre si. Uma alteração na direção do crescimento dos processos nasais pode ser uma explicação para o estabelecimento deste tipo de fissura (Cohen Jr 2000). Já, a formação de uma fissura de palato secundário se dá entre a sétima (Cate 2001) e décima segunda (Diewert 1983 e Sperber 1989) semana de vida intrauterina e pode resultar de: 1) falha das cristas palatinas de se contatarem por causa de uma deficiência de crescimento ou de um distúrbio no mecanismo de elevação das cristas; 2) falha das 
cristas em se fundirem após o contato ter sido estabelecido devido ao fato de o epitélio de revestimento não se romper ou não ser reabsorvido; 3) ruptura após ter ocorrido a fusão das cristas; ou, 4) fusão e consolidação defeituosa do mesênquima das cristas palatinas (Cate 2001).

Segundo relatório divulgado pela Organização Mundial da Saúde, em 2002 (Shaw e Semb 2007), a etiologia das malformações craniofaciais, incluindo as fissuras orofaciais, é complexa e multifatorial. Os fatores que podem interferir sobre o mecanismo intrínseco causando a má formação embriológica são os fatores genéticos, os fatores ambientais e a interação de ambos. Em se tratando dos fatores genéticos estão incluídas as alterações de um único gene, interações poligênicas e desordens cromossômicas. Estudos publicados por Kondo et al (2002) descrevem haver o envolvimento de genes como TGFB, MSX1 e IRF6 com a etiologia das fissuras orofaciais. Os fatores ambientais podem, por meio do organismo da mãe, exercer efeitos desfavoráveis à evolução embrionária. São citados na literatura o estado nutricional materno (hipo e hipervitaminoses), o tabagismo e o consumo excessivo de álcool durante o período gestacional, exposições ocupacionais a algumas substâncias químicas (solventes e pesticidas), exposições a raios $\mathrm{X}$, doenças maternas durante a gravidez (epilepsia, infecções virais) e o uso inadvertido de alguns medicamentos como os benzodiazepínicos e os corticoesteróides.

A manifestação clínica das fissuras é variada, envolvendo lábio, palato ou ambos, com extensões e amplitudes diferentes. Segundo Spina et al (1972) e Silva Filho et al (1992), as fissuras podem ser divididas em quatro grupos conforme mostrado no quadro 1 , sendo que os três primeiros grupos tomam como ponto de reparo anatômico o forame incisivo (Figura 1). As fissuras pré-forame incisivo 
(Figuras 2A e 2B) são assim chamadas por envolverem o lábio superior, o processo alveolar superior e o palato primário estendendo-se até o forame incisivo. São classificadas como completas quando envolvem as três estruturas acima citadas e incompletas quando envolvem apenas uma ou duas destas estruturas Quanto à localização em que se situam podem ser unilaterais, bilaterais e medianas. As fissuras transforame incisivo são aquelas que acometem o lábio superior, o processo alveolar superior, o palato primário, passando pelo forame incisivo e, finalmente, chegando ao palato secundário. Podem ainda ser classificadas como unilaterais (Figuras 2C e 2D), bilaterais (Figuras 2E e 2F) e medianas. Já, as fissuras pósforame incisivo são aquelas que acometem exclusivamente o palato secundário. Podem ser divididas em completas, quando acometem toda a extensão do palato secundário envolvendo inclusive a úvula, e incompletas quando acometem parte da extensão do palato secundário não chegando até o forame incisivo. As fissuras raras da face (Figura 2H) são fissuras desvinculadas do palato primário e secundário acometendo estruturas extra-bucais como a maxila e mandíbula. 
Quadro 1 - Classificação das fissuras, segundo Spina et al (1972) e modificada por Silva Filho et al (1992), e adotada no HRAC-USP

\begin{tabular}{|c|c|c|}
\hline \multirow{6}{*}{$\begin{array}{l}\text { Grupo I } \\
\text { Fissuras pré-forame incisivo }\end{array}$} & \multirow[b]{2}{*}{$\begin{array}{l}\text { Unilateral } \\
\text { (direita ou esquerda) }\end{array}$} & Incompleta \\
\hline & & Completa \\
\hline & \multirow[b]{2}{*}{ Bilateral } & Incompleta \\
\hline & & Completa \\
\hline & \multirow[b]{2}{*}{ Mediana } & Incompleta \\
\hline & & Completa \\
\hline \multirow{3}{*}{$\begin{array}{l}\text { Grupo II } \\
\text { Fissuras } \quad \text { transforame } \\
\text { incisivo }\end{array}$} & \multicolumn{2}{|c|}{ Unilateral (direita ou esquerda) } \\
\hline & \multicolumn{2}{|l|}{ Bilateral } \\
\hline & \multicolumn{2}{|l|}{ Mediana } \\
\hline \multirow{2}{*}{$\begin{array}{l}\text { Grupo III } \\
\text { Fissuras pós-forame incisivo }\end{array}$} & \multicolumn{2}{|l|}{ Incompleta } \\
\hline & \multicolumn{2}{|l|}{ Completa } \\
\hline $\begin{array}{l}\text { Grupo IV } \\
\text { Fissuras raras da face }\end{array}$ & \multicolumn{2}{|c|}{ Fissuras desvinculadas do palato $1^{\text {ario }}$ e $2^{\text {ario }}$} \\
\hline
\end{tabular}




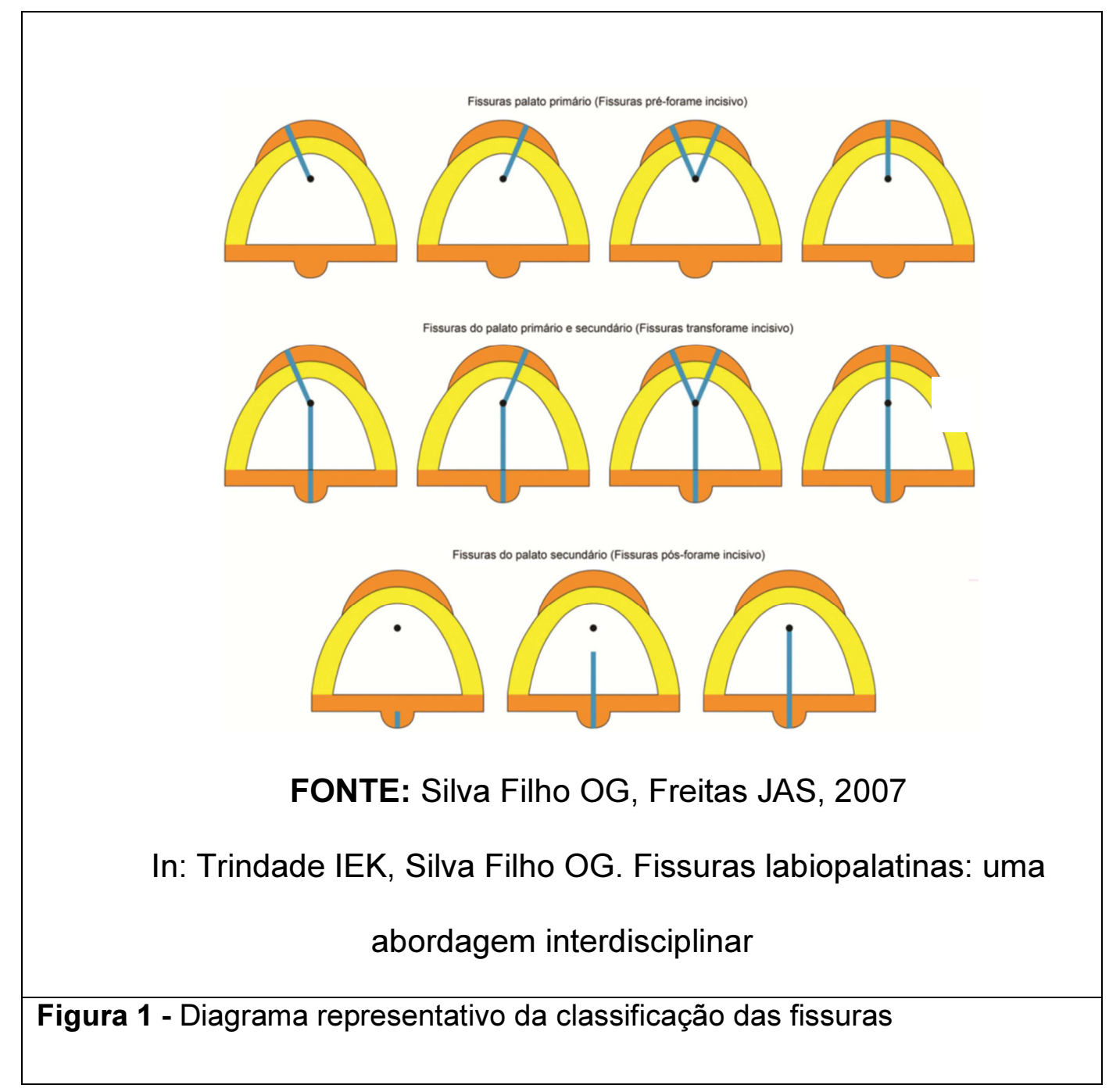




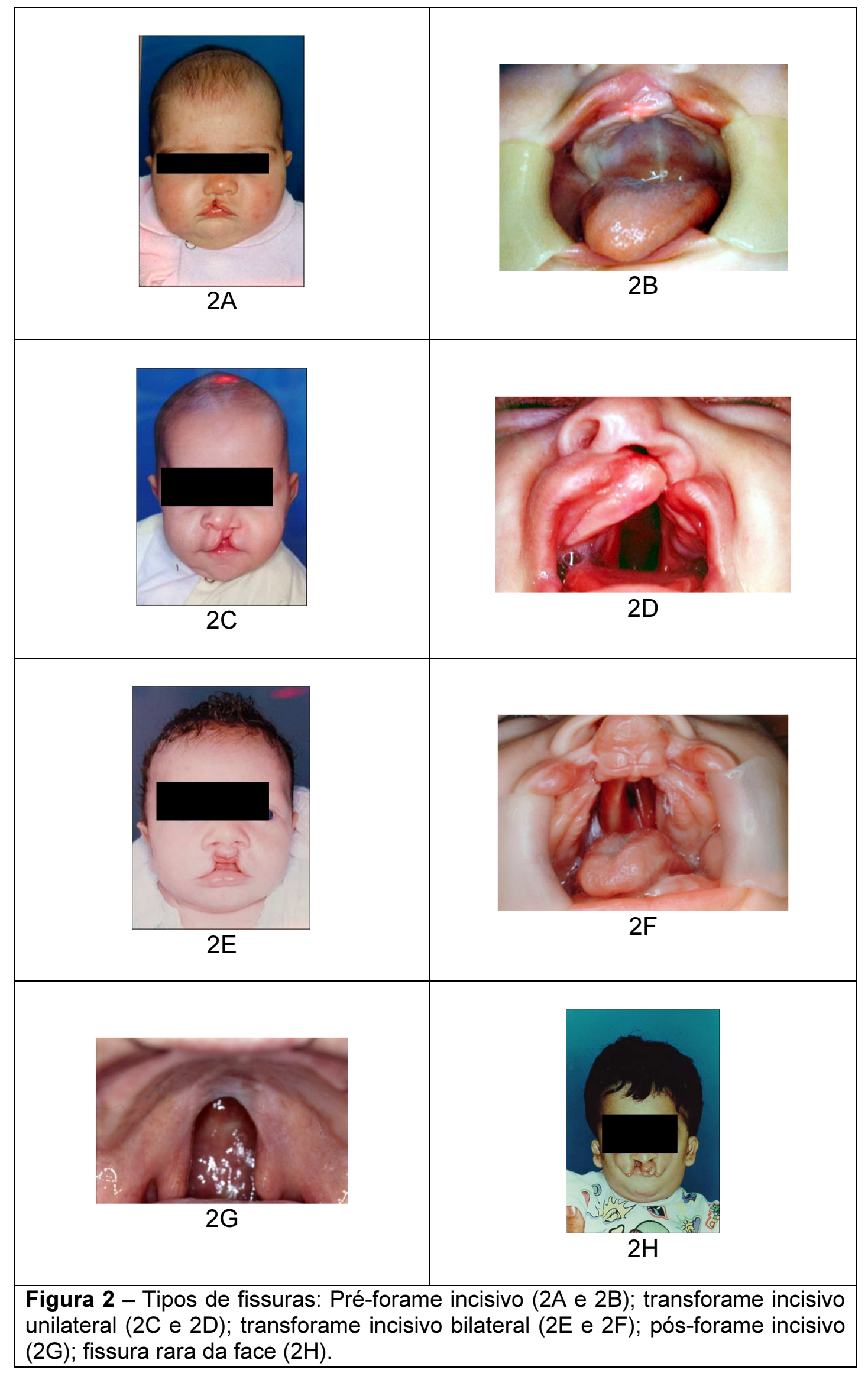




\subsection{Considerações sobre o protocolo reabilitador do indivíduo com fissura labiopalatina}

As fissuras orofaciais requerem tratamento altamente especializado multiprofissional e interdisciplinar. O envolvimento anatômico das fissuras define o protocolo de tratamento a ser instituído para a sua reabilitação, que se inicia com a equipe de cirurgia plástica, reconstituindo o lábio (queiloplastia), por volta dos 3 meses de idade, e o palato (palatoplastia), realizada por volta de 12 meses (Silva Filho et al 1992). As chamadas cirurgias plásticas primárias, queiloplastia e palatoplastia, reconstroem tecido mole.

Já, o defeito ósseo alveolar presente nas fissuras pré-forame incisivo e transforame incisivo persiste até a dentadura mista, por volta dos 10 anos de idade, quando necessita ser reparado. O tratamento cirúrgico do defeito ósseo alveolar é realizado pelo cirurgião buco-maxilo-facial e compreende o enxerto ósseo alveolar (EOA), cujo objetivo primordial é fornecer tecido ósseo para a região da fissura e, por conseqüência, dar continuidade ao rebordo alveolar. Esse procedimento é, em geral, realizado durante a dentadura mista, imediatamente antes da irrupção do canino permanente adjacente à área da fissura alveolar (Silva Filho et al 1995 e Silva Filho et al 2000).

O tratamento ortodôntico é de fundamental importância para o prognóstico do EOA e deve incluir, no período pré-operatório, a correção de mordidas cruzadas anteriores e posteriores. A ortodontia pós-operatória visa o alinhamento e nivelamento dentário com vistas ou não à cirurgia ortognática, especialmente nos casos diagnosticados com o índice oclusal Goslon 4 e 5 (Mars et al 1987). A indicação da cirurgia ortognática na maturidade esquelética ocorre quando a 
discrepância maxilomandibular ultrapassou a possibilidade de ação dos recursos ortodônticos e ortopédicos. Esta cirurgia tem por finalidade corrigir as desarmonias oclusais, em especial a classe III, provendo ao paciente uma relação interoclusal equilibrada (Silva Filho et al. 2011).

Vale ressaltar que, de acordo com Silva Filho et al (2007), embora a fissura altere a conformação anatômica da maxila, sua presença não impede o crescimento da face, conforme ilustram as figuras $3 \mathrm{~A}$ e $3 \mathrm{~B}$. Entretanto, após as cirurgias plásticas primárias, a face passa a crescer sob influência marcante da queiloplastia. Assim, paradoxalmente, as cirurgias corretoras, que têm o papel de restaurar a forma e a função da maxila e das estruturas a ela relacionadas, podem causar efeitos deletérios adicionais, por restrição do crescimento maxilar, contribuindo para as deformidades características observadas em portadores dessas malformações, como a retrusão nasomaxilar acompanhada de mordida cruzada anterior, e, a mordida cruzada posterior unilateral ou bilateral, observadas, principalmente, a partir da dentadura mista. A maxila atrésica e retroposicionada confere ao indivíduo com fissura operada um perfil côncavo característico (Figuras 3C e 3D).

Em pacientes com fissura transforame incisivo bilateral, as alterações características anatômicas acima referidas manifestam-se de forma mais intensa, devido à extensão da fissura e ao acometimento de ambos os lados da face. Por esta razão, o tratamento cirúrgico é direcionado para o reposicionamento da maxila nos três sentidos do espaço, envolvendo procedimentos ortopédicos como a expansão rápida e a tração reversa da maxila e, nos casos de discrepância sagital grave, a distração osteogênica elou a cirurgia ortognática (Aiello 2005). 


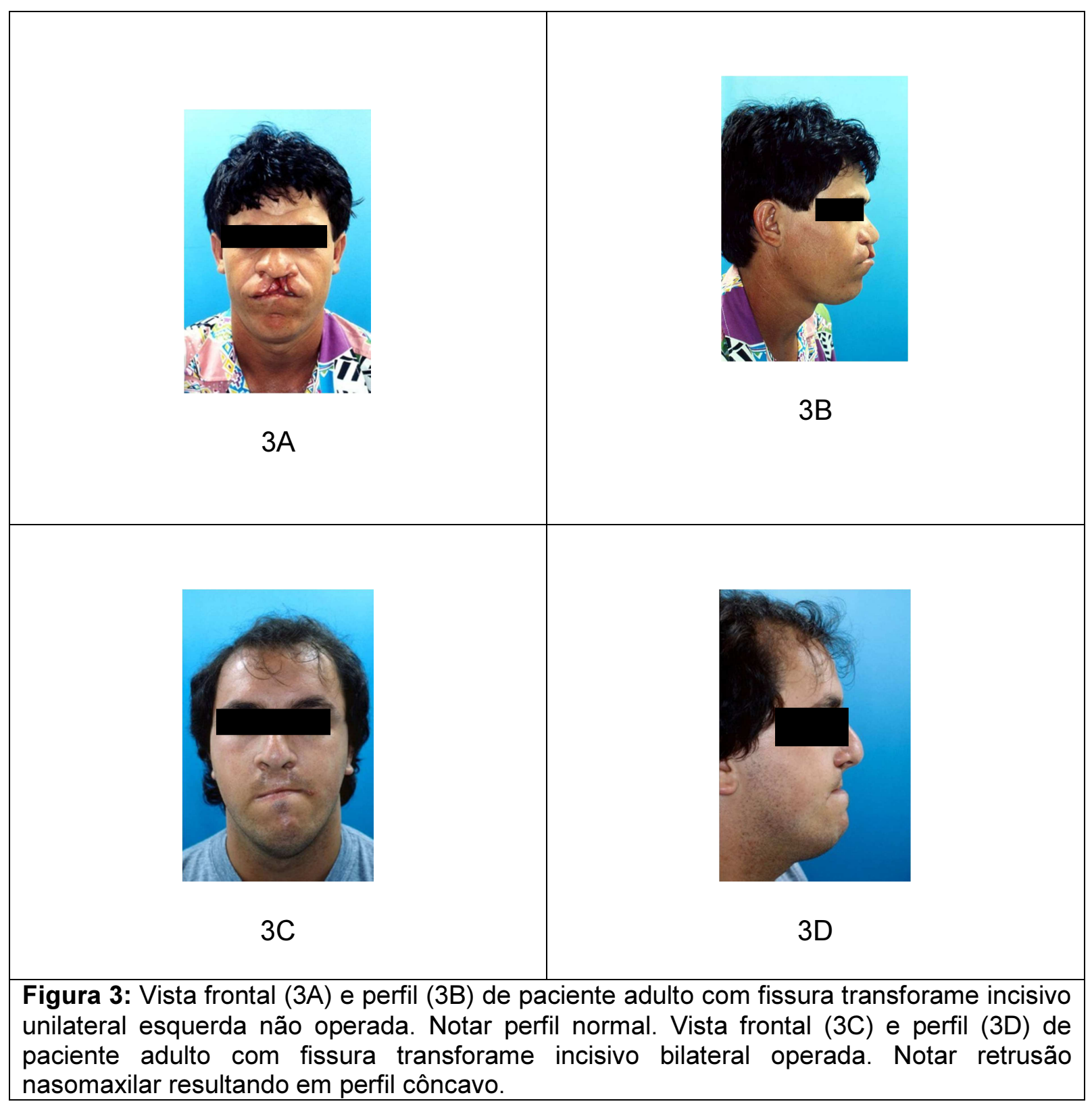


Em aproximadamente 20 a $30 \%$ dos pacientes com fissura transforame incisivo unilateral, a cirurgia ortognática se torna necessária para a finalização do tratamento reabilitador (Silva Filho 2007). Nestes pacientes, a cirurgia envolve, via de regra, a osteotomia Le Fort I para avanço maxilar, associada ou não a movimentos verticais da maxilar, quando necessários. Também, em muitos casos, se faz necessária a osteotomia para a retrusão ou até mesmo avanço mandibular, na dependência do posicionamento antero-posterior da mandíbula.

Com a relação interarcos refeita pela cirurgia ortognática, o eventual planejamento protético passa a ser possível, visando a estética e a reabilitação oclusal final. (Silva Filho et al 2011)

\subsection{Considerações sobre as vias aéreas superiores de indivíduos com fissura labiopalatina}

Do ponto de vista fisiológico, $60 \%$ dos indivíduos com fissura labiopalatina apresentam as vias aéreas comprometidas. Isto porque, a deficiência de crescimento maxilar, comum neste grupo de indivíduos, leva à deformidades como desvio de septo nasal, hipertrofia das conchas nasais e as alterações do assoalho nasal. Estas alterações acabam por reduzir as dimensões internas da cavidade nasal, aumentam a resistência ao fluxo aéreo respiratório, e em parcela considerável dos pacientes, produzem respiração oral de suplência, que pode prejudicar 0 desenvolvimento craniofacial, comprometer a função de vias aéreas inferiores e a produção da fala. (Bertier e Trindade 2007) 
As fissuras labiopalatinas reconhecidamente afetam, também, a forma e a função nasal. Nas fissuras unilaterais, as duas porções do músculo orbicular do lábio superior, criadas pela fenda, tendem a tracionar as estruturas nasais em direções opostas; no lado da fissura, a força é exercida sobre a base alar externa e do lado oposto, sobre a base da columela. Como conseqüência, o nariz sofre desvio da pirâmide nasal para o lado não-fissurado e achatamento da narina no lado da fissura. Já, nas fissuras bilaterais, quando simétricas, o nariz não sofre desvio, e as alterações mais evidentes são a columela muito curta, ou mesmo ausente, e a ponta nasal achatada e alargada; nas formas assimétricas, menos frequentes, o desequilíbrio de forças produz deformidades similares àquelas das fissuras unilaterais (Bertier e Trindade 2007).

Estudos do Laboratório de Fisiologia do HRAC/USP (Fukushiro e Trindade 2005, Trindade, Bertier e Sampaio-Teixeira 2009 e Trindade et al, 2010) têm demonstrado, por meio de avaliação rinométrica e rinomanométrica, que o nariz dos pacientes com fissura, independentemente da fase da vida em que se encontram, apresentam as dimensões internas reduzidas, ou seja, é obstruído, e que procedimentos como a rinosseptoplastia e a expansão rápida da maxila, favorecem o aumento das áreas e dos volumes nasais destes pacientes. Demonstrou-se, ainda, que a área de secção transversa mínima em indivíduos adultos com fissura transforame incisivo bilateral apresentou-se menor do que em indivíduos da mesma faixa etária, com fissura transforame incisivo unilateral. Os autores atribuíram esta diferença a um déficit de crescimento que parece ocorrer nos casos bilaterais, comparativamente aos unilaterais. 
Contudo, pouco se sabe sobre o efeito das fissuras sobre a faringe. Telerradiografias em norma lateral de crianças com fissura labiopalatina foram comparadas com as de indivíduos sem fissura e demonstrou-se uma redução das dimensões faríngeas nos pacientes com fissura (Smahel e Müllerová 1992). Os autores associaram esta redução ao retroposicionamento da maxila comum nas crianças com fissura levando à uma redução da nasofaringe esquelética e consequentemente do espaço aéreo faríngeo.

Como pode ser observado nos estudos citados, diversas formas de se avaliar o espaço aéreo de um paciente, são descritas na literatura, como a rinometria acústica, videofluoroscopia, nasofaringoscopia, ressonância magnética, rinomanometria, cefalometria e tomografia. Todos esses métodos são utilizados com frequência na rotina clínica diária no nosso hospital. A maioria dos estudos clássicos que relacionam discrepâncias maxilomandibulares e espaço aéreo foram realizados por meio de Cefalometria, exame este que é amplamente utilizado na rotina dos profissionais ligados a ortodontia e cirurgia bucomaxilofacial. Contudo, esta radiográfica apresenta apenas dois planos e uma série de sobreposições oriundas da técnica de obtenção da imagem. Neste quesito a tomografia computadorizada, em especial a de feixe cônico é atualmente a opção mais viável para os profissionais da odontologia devido a uma série de vantagens que serão descritas com maior ênfase no próximo tópico. 


\subsection{Considerações sobre a tomografia computadorizada de feixe cônico e aferição tridimensional das vias aéreas superiores}

O uso da tomografia computadorizada de feixe cônico (TCFC), a ser utilizada no presente estudo, tem sido cada vez mais utilizada na área odontológica, para a análise da região maxilofacial. Isto porque as doses de radiação emitidas são 1/15 menor do que a dose que um tomógrafo computadorizado convencional, além de prover imagens com um alto índice de resolução (Ludlow et al 2006). Ademais, a TCFC permite a obtenção de imagens em 3 dimensões, projeções multiplanares tais como, imagens panorâmicas, periapicas, oclusais e cortes transversais, fornecendo informações mais detalhadas e dados clínicos adicionais que não são visualizadas nas radiografias convencionais, melhorando o diagnóstico e o plano de tratamento (Hamada et al 2005, Ludlow et al 2006).

A tomografia computadorizada de feixe cônico (TCFC), por ser tridimensional (3D), possibilita avaliar o espaço aéreo e estruturas circunvizinhas, determinando medidas tridimensionais da naso, oro e hipofaringe, como a área de maior constricção, o volume e a menor dimensão anteroposterior e lateral da faringe de forma precisa e confiável (Oberoi et al 2009).

O interesse na avaliação tomográfica das vias aéreas reside no fato de que imagens volumétricas permitem a identificação de pacientes com o espaço aéreo reduzido e que, portanto, estariam em risco para o estabelecimento de desordens obstrutivas respiratórias, entre elas a apneia obstrutiva do sono (Hatcher 2012). Ogawa et al (2007) demonstraram uma correlação positiva entre indivíduos diagnosticados com síndrome da apneia obstrutiva do sono, índice de massa 
corpórea elevada e volume reduzido da via aérea, aferida por meio de imagens tomográficas, quando comparados a indivíduos controle.

Neste sentido, tem se observado um crescente interesse na investigação da correlação entre as dimensões das vias aéreas, a presença de discrepâncias maxilomandibulares e a apneia obstrutiva do sono. Isto porque, é fato notório que as cirurgias ortognáticas para correção das discrepâncias maxilomandibulares são capazes de alterar as dimensões das vias aéreas superiores. Hernández-Alfaro et al (2011) observaram um aumento de quase $40 \%$ no volume total da via aérea superior após cirurgia Le Fort I de avanço de maxila em pacientes com deformidade esquelética do tipo classe III.

Outro grupo de autores, por sua vez, demonstraram que a cirurgia bimaxilar para correção da má-oclusão de classe III, ou seja, avanço de maxila e retroposição de mandíbula, aumentou o volume da via aérea na região mais superior em $12 \%$, diminuiu o volume da porção mais posterior em $14 \%$, mantendo assim inalterado o volume total. (Lee at al 2012). Em estudo subsequente, Lee et al (2013), observaram que a retroposição cirúrgica da mandíbula levou a uma redução de aproximadamente $30 \%$ no volume da oro e hipofaringe. Contudo, não são muitos os estudos que avaliam dimensões faríngeas em indivíduos com fissura labiopalatina. Dentre os poucos estudos que avaliaram as vias aéreas por meio de TCFC nesta população, há total falta de consenso.

Ao comparar o espaço aéreo em pacientes adultos com fissura de palato isolada não reparada em relação ao de pacientes adultos sem fissura, $\mathrm{Xu}$ et al (2013) destacou que a presença da fissura não reparada configura uma maior área do espaço aéreo na região do plano palatino. Este fato faz com que o volume da 
nasofaringe e da orofaringe na população estudada se apresentasse substancialmente aumentado em relação ao do grupo de paciente sem fissura. Diferenças de volume da hipofaringe entre os grupos não foram observadas. Por fim, os autores concluíram que os pacientes com fissura de palato isolada não reparada possuem um maior volume faríngeo que pacientes sem fissura.

Da mesma forma, Aras, Olmez e Dogan (2012) encontraram volumes faríngeos maiores nos pacientes com fissura labiopalatina unilateral em comparação a pacientes sem fissura, porém, estas diferenças não foram consideradas significantes. Diferenças estatisticamente significantes foram observadas entre o volume da cavidade nasal, tendo o grupo com fissura o menor valor. Em novo estudo, Olmez, Aras e Dogan (2014), mostram que os maiores volumes encontramse na região média e inferior da faringe dos indivíduos com fissura, porém, mais uma vez, as únicas diferenças significativas se deram nos volumes da cavidade nasal, substancialmente diminuídos no grupo com fissura. Desta vez, estes pesquisadores tentaram associar diferenças nos graus de má-oclusão do grupo com fissura com as vias aéreas, dividindo este grupo em subgrupos, de acordo com o índice Goslon. Maior valor deste índice indica maior a discrepância oclusal. Este índice também associa a extensão da fissura com os danos causados por ela nas estruturas circundantes como, por exemplo, nos maxilares e na cavidade nasal. No entanto, neste estudo não houve correlação entre o índice Goslon e o comprometimento das vias aéreas, fato que os autores atribuem ao numero reduzido da amostra.

Por outro lado, Celigoku et al (2014), ao comparar o volume do espaço aéreo entre pacientes com fissura labiopalatina unilateral completa e pacientes sem fissuras, demonstraram que o grupo de pacientes acometidos por fissura tiveram o valores de volume orofaringe, nasofaringe e volume total menores que o controle, 
porém foram estatisticamente menores apenas na região de orofaringe. Apesar de Diwakar (2014) avaliarem uma amostra menor comparativamente aos outros estudos ( $n=22$ ), os autores corroboram os resultados de Celigoku et al (2014), pois encontraram volumes faríngeos reduzidos no grupo com fissura, mais especificamente, a nasofaringe e a orofaringe, sendo estatisticamente significante apenas a diferença na nasofaringe, em relação a pacientes sem fissura.

Por fim, Pimenta et al (2014), utilizando o software Mimics, demonstraram recentemente que não há diferença no volume da nasofaringe de pacientes com fissura e sem fissura por meio de TCFC. Da mesma forma, Cheung e Oberoi (2012) demonstraram, por meio de estudo volumétrico, utilizando TCFC, que a faringe dos pacientes com fissura apresentava dimensões similares à de pacientes sem fissura, apesar de observarem neste último grupo valores numericamente maiores que os do controle.

Vale ressaltar que nos estudos supracitados não houve um controle do padrão dento facial esquelético estudado. Apenas Celigoku et al (2014) reportam ter incluído no grupo controle tão somente pacientes com oclusão classe I de Angle. Isto significa que, em uma mesma amostra, os autores dos demais estudos aqui apresentados podem ter avaliado pacientes classe I de Angle, que apresentam uma relação maxilomandibular normal ou pacientes classe II ou III, que apresentam reconhecidamente alteração do espaço aéreo posterior inerente à discrepância maxilomandibular (Grauer et al 2009, Kim et al 2010, El e Palomo 2011, Claudino et al 2013, El e Palomo 2013 e Zheng et al 2014).

Estudos que avaliaram as alterações dimensionais das vias aéreas superiores após cirurgia ortognática em pacientes com fissuras labiopalatinas não foram 
encontrados. Assim, considerando-se o baixo número de estudos que avaliem satisfatoriamente o volume faríngeo desta população, a falta de controle de discrepâncias dento-facial esquelética, e, principalmente a ausência de consenso observada nos resultados encontrados na literatura, tornou-se pertinente avaliar tridimensionalmente o espaço aéreo faríngeo dos pacientes com fissura labiopalatina e discrepâncias maxilomandibulares por meio de tomografia computadorizada de feixe cônico. É neste contexto que se insere a presente proposta. 

2 OBJetivos 



\section{OBJETIVOS}

Este estudo teve como objetivo caracterizar tridimensionalmente o espaço aéreo faríngeo do paciente com fissura labiopalatina unilateral, acompanhada de discrepância maxilomandibular caracterizada por relação oclusal classe III de Angle, por meio da análise do volume e da área seccional mínima, utilizando imagens de tomografia computadorizada de feixe cônico. 


3 MATERIAL E MÉTOdOS 



\section{MATERIAL E MÉTODOS}

\subsection{CASUÍSTICA}

Considerando um erro padrão de $10 \%$ e uma variação esperada de área e volume maiores que 30\% (Cheung e Oberoi 2012), estimou-se uma amostra de 30 pacientes por grupo. Assim, após a aprovação pelo Comitê de Ética em Pesquisa do HRAC/USP (ANEXO 1) e assinatura do "Termo de Compromisso de Manuseio de Informações" (ANEXO 2) pelos pesquisadores, foram avaliadas 60 tomografias computadorizadas de feixe cônico do banco de dados do HRAC/USP e do banco de dados de dois serviços de cirurgia bucomaxilofacial da cidade de Bauru-SP.

Assim, a amostra do estudo foi composta por dois grupos de pacientes: 1) Grupo Controle (GC): 30 tomografias de pacientes sem fissura e com discrepância maxilomandibular do tipo classe III de Angle, e, 2) Grupo Fissura (GF): 30 tomografias de pacientes com fissura labiopalatina unilateral e com discrepância maxilomandibular do tipo classe III de Angle.

\subsection{MÉTODOS}

Para a realização do estudo, foram utilizadas tomografias computadorizadas de feixe cônico obtidas retrospectivamente, para fins de planejamento cirúrgico, no tomógrafo i-CAT Next Generation (ISI-iCAT Imaging System - cone beam, Next Generation i-CAT®), com as seguintes especificações: campo de visão (FOV) de no mínimo 16x13cm, tempo de exposição de 26,9 segundos, $120 \mathrm{Kv}, 37,07 \mathrm{~mA}$ resolução de 0,25 voxels. As imagens foram importadas no formato DICOM (Digital 
Imaging and Communications in Medicine) para que pudessem ser visualizada no software Dolphin Imaging 11.0.

Estes arquivos foram então avaliados por meio do software Dolphin Imaging 11.0, que é capaz de reformatar a imagem da via aérea em 3 dimensões (3D), ou seja, gerar uma imagem volumétrica da via aérea superior. Para tanto, pontos anatômicos do esqueleto fixo da face e de estruturas anatômicas do pescoço foram demarcados afim de se padronizar um polígono que delimitasse a área de interesse a ser avaliada e tornasse o método reprodutível. Na prática, esta padronização viabilizou a obtenção de um polígono com o mesmo formato no outro momento da análise e por outro avaliador, bem como a comparação entre as medidas intra- e intergrupos.

A partir do corte sagital mediano, foram demarcados os pontos anatômicos Ba (Básio), S' (borda anterosuperior da sela pituitária), C4 (limite anteroinferior da $4^{\text {a }}$ vértebra cervical) e H (limite anteroinferior do osso hióide), para obtenção de um polígono que delimita a área faríngea; na seqüência, procedeu-se a marcação do espaço aéreo contido neste polígono com a ferramenta "seed points", a qual realiza a coloração automática da área de interesse faríngea pelo padrão do software; assim, o software gera uma reformatação tridimensional da imagem da via aérea, na qual se obtém os valores numéricos de volume $(\mathrm{V})$, expressos $\mathrm{em}^{\mathrm{cm}}{ }^{3}$, bem como a área seccional mínima (ASM), expressa em $\mathrm{mm}^{2}$, que representa a área de maior constrição da faringe, conforme ilustram as Figuras 4 e 5 . 


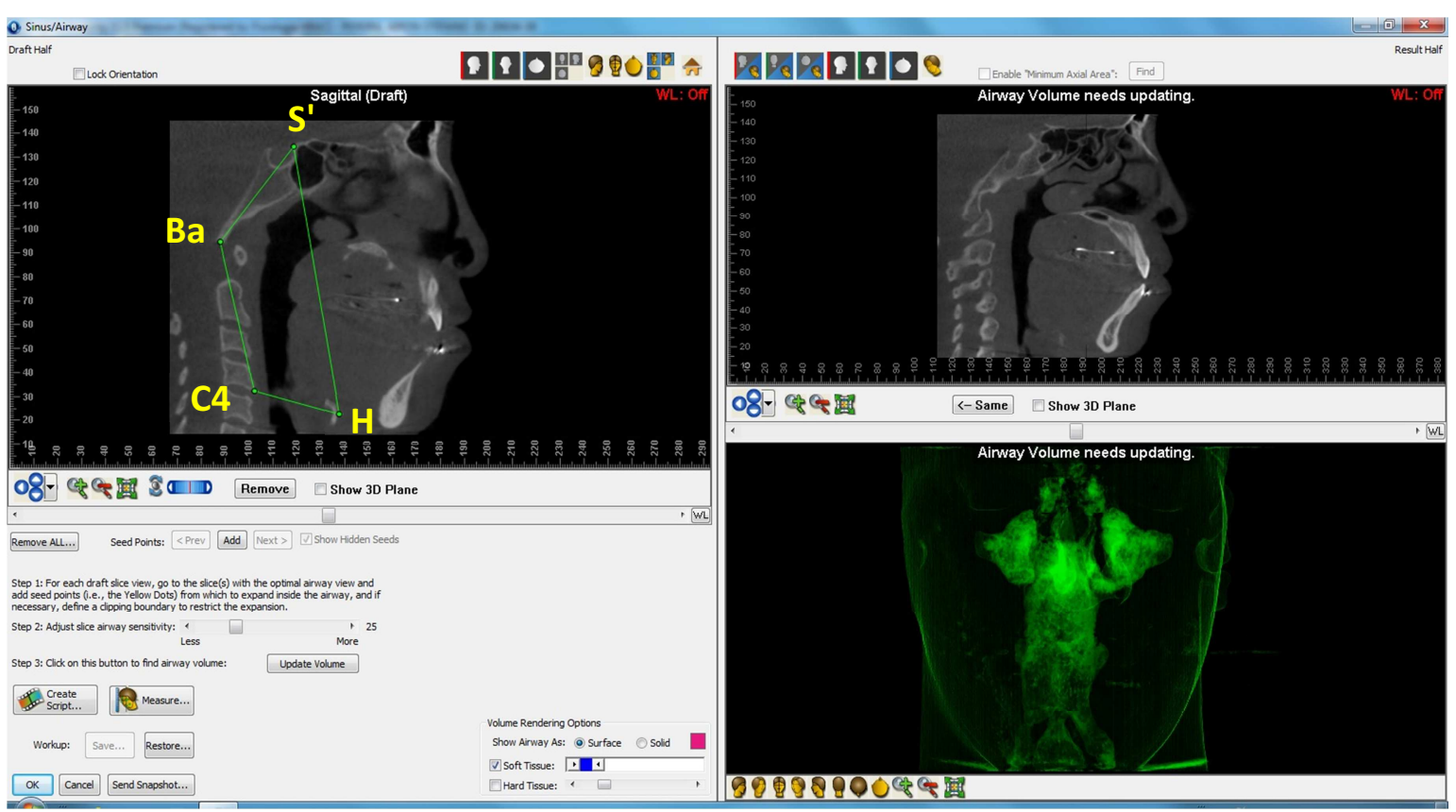

Figura 4: Tela do programa Dolphin Imaging 11.0 que mostra o corte sagital mediano, à esquerda, e a marcação dos pontos anatômicos: Ba (Básio), $S$ '(ponto mais anterosuperior da sela pituitária), C4 (limite anteroinferior da $4^{\mathrm{a}}$ vértebra cervical) e H (limite anteroinferior do osso hióide) para obtenção do polígono que delimita a área faríngea;

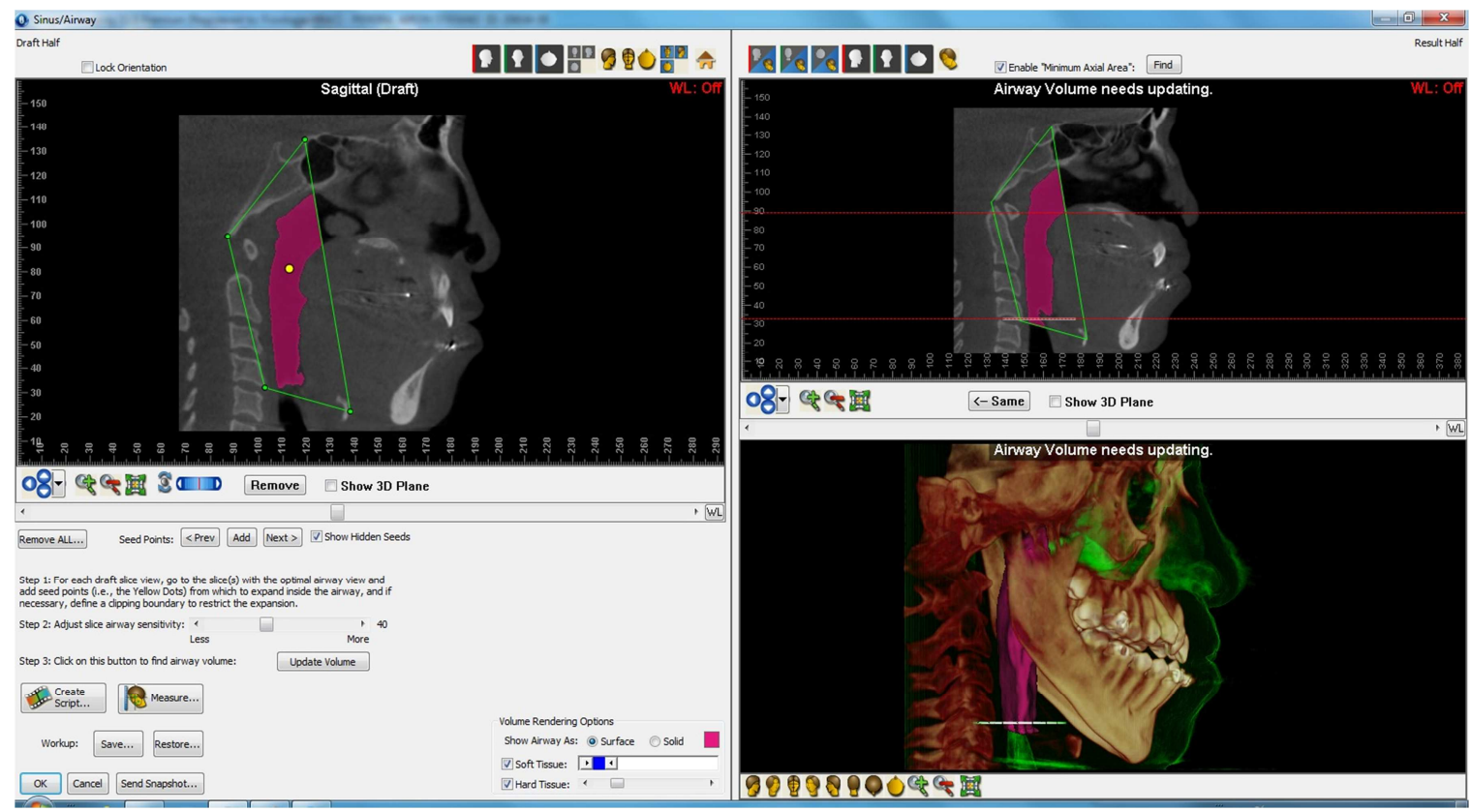

Figura 5: À esquerda: marcação do espaço aéreo e coloração da área de interesse faríngea; à direita: reformatação do volume (visão tridimensional) e obtenção dos valores numéricos, expressos em $\mathrm{mm}^{3}$; e determinação da área seccional mínima, expressa em $\mathrm{mm}^{2}$, que representa a área de maior constrição da faringe. 

As imagens foram analisadas por dois avaliadores, cirurgiões bucomaxilofaciais, treinados e calibrados para a realização das medidas. $O$ avaliador 1 (TFL), avaliador principal, realizou a leitura das imagens em dois tempos distintos (T1 e T2), com intervalo de 1 mês entre as medidas, com o propósito de se aferir a reprodutibilidade intra-avaliador. Os valores médios de área e volume, obtidos nas duas medições, foram considerados para análise

Já o avaliador 2 (IKTS), realizou a leitura das imagens em 17\% da amostra, que correspondeu a 10 tomografias, ou seja, 5 exames de cada grupo, afim de se averiguar a concordância entre as medidas, ou seja, a reprodutibilidade interavaliador.

\subsection{ANÁLISE DOS DADOS}

A reprodutibilidade intra-avaliador foi calculada pelo Coeficiente de Correlação Intraclasse (Intraclass correlation coefficient - ICC) (Fleiss JL 1999) que adota a seguinte pontuação: ICC $<0,40=$ concordância fraca; ICC de 0,4-0,75= concordância moderada, e, ICC>0,75 = concordância alta.

Considerando que as variáveis volume e área seguiram distribuição normal, os resultados dos grupos foram expressos como média \pm desvio padrão $(X \pm D P)$. $A$ significância das diferenças entre os grupos foram avaliadas pelo teste " $t$ " de Student para amostras independentes. A correlação entre as variáveis área e volume, e, área e idade, nos diferentes grupos, foi aferida pelo Coeficiente de correlação de Pearson. Valores de $p<0.05$ foram considerados significantes. 

4 Resultados 



\section{RESULTADOS}

Considerando que a concordância das medidas da ASM e do V médios para o avaliador 1, entre os tempos T1 e T2, para os GC e GF, foi alta e, ainda, que a concordância das medidas da ASM e do V médios entre os dois avaliadores também foi alta (Tabela 1), para fins de análise, serão apresentados e analisados os valores médios $(T 1+T 2 / 2)$ de ASM e do $\mathrm{V}$, do avaliador 1.

\section{1 ÁREAS SECCIONAIS MÍNIMAS FARÍNGEAS}

Na Tabela 2 são mostrados os valores individuais e médios das duas medições (T1 e T2) do GC, realizadas pelos avaliadores 1 e 2, bem como os valores médios das ASM faríngeas, expressos em $\mathrm{mm}^{2}$. Os valores médios ( $\left.\pm \mathrm{DP}\right)$ da ASM, dos 30 indivíduos do GC, corresponderam a $188,8 \pm 110,2 \mathrm{~mm}^{2}$. Já, no GF, os valores corresponderam a 158,6 $\pm 99,1 \mathrm{~mm}^{2}$, conforme mostra a Tabela 3 . Apesar de menores, não foram encontradas diferenças estatisticamente significante entre as ASM do GF em relação ao GC. Estes resultados estão ilustrados na Figura 6. 
Tabela 1- Valores do Coeficiente de Correlação Intraclasse (ICC) (Fleiss JL 1999) das medidas da área seccional mínima (ASM) e do volume (V) médios do avaliador 1, nos tempos T1 e T2, para os grupos controle (GC) e com fissura(GF) e entre os avaliadores 1 e 2 .

\section{Avaliador 1}

\section{ASM (GC) $\quad$ ASM (GF) $\quad$ V (GC) V (GF)}

$\begin{array}{lllll}\text { Avaliador } 1 & 1,00 & 0,99 & 0,99 & 0,96\end{array}$

$\begin{array}{lllll}\text { Avaliador } 2 & 0,99 & 0,99 & 1,00 & 0,96\end{array}$


Tabela 2 - Valores individuais de duas medições (T1 e T2) realizadas pelos avaliadores 1 e 2 e valores médios das áreas seccionais mínimas (ASM) faríngeas, expressos em $\mathrm{mm}^{2}$, do grupo controle ( $\mathrm{GC}=30$ indivíduos sem fissura labiopalatina), aferidos por tomografia computadorizada de feixe cônico.

\begin{tabular}{|c|c|c|c|c|c|c|c|}
\hline & & & & & Avaliador 1 & & Avaliador 2 \\
\hline Grupo & Nome & Sexo & Idade & $\begin{array}{c}\text { ASM } \\
\text { T1 }\end{array}$ & $\begin{array}{c}\text { ASM } \\
\text { T2 } \\
\end{array}$ & ASM MÉDIA & $\begin{array}{c}\text { ASM } \\
\text { MÉDIA }\end{array}$ \\
\hline \multirow{30}{*}{$\begin{array}{c}\text { Sem } \\
\text { Fissura } \\
(n=30)\end{array}$} & TGL & $\mathrm{F}$ & 23 & 84,2 & 84,7 & 84,5 & - \\
\hline & JFD & $\mathrm{F}$ & 22 & 68,8 & 67,1 & 68,0 & 69,9 \\
\hline & ADN & $M$ & 44 & 39,0 & 41,3 & 40,2 & - \\
\hline & DIO & $M$ & 19 & 103,1 & 93,4 & 98,3 & - \\
\hline & GMO & $M$ & 13 & 96,7 & 92,1 & 94,4 & - \\
\hline & JCS & $M$ & 34 & 156,9 & 133,7 & 145,3 & - \\
\hline & LHS & $M$ & 30 & 183,9 & 159,0 & 171,5 & 164,0 \\
\hline & MRL & $M$ & 50 & 76,3 & 56,3 & 66,3 & - \\
\hline & VGO & $M$ & 54 & 102,0 & 92,8 & 97,4 & - \\
\hline & $\mathrm{AL}$ & $\mathrm{F}$ & 20 & 275,6 & 268,1 & 271,9 & - \\
\hline & AS & $\mathrm{F}$ & 36 & 131,1 & 125,8 & 128,5 & - \\
\hline & BT & $M$ & 21 & 275,9 & 260,7 & 268,3 & - \\
\hline & $\mathrm{CV}$ & $\mathrm{F}$ & 45 & 231,2 & 256,9 & 244,1 & 266,2 \\
\hline & DP & $\mathrm{F}$ & 24 & 166,8 & 164,3 & 165,6 & - \\
\hline & $\mathrm{FC}$ & $M$ & 47 & 72,3 & 70,3 & 71,3 & - \\
\hline & FJr & $M$ & 18 & 161,7 & 161,6 & 161,7 & - \\
\hline & FS & $M$ & 33 & 372,9 & 358,1 & 365,5 & - \\
\hline & GDP & $\mathrm{F}$ & 19 & 178,4 & 171,4 & 174,9 & - \\
\hline & GLEL & $M$ & 25 & 330,9 & 344,8 & 337,9 & - \\
\hline & GRAL & $F$ & 28 & 145,7 & 140,4 & 143,1 & - \\
\hline & ISF & $M$ & 39 & 125,7 & 112,0 & 118,9 & 121,4 \\
\hline & $\mathrm{JB}$ & $\mathrm{F}$ & 19 & 223,6 & 222,6 & 223,1 & - \\
\hline & JRR & $M$ & 33 & 226,3 & 229,1 & 227,7 & - \\
\hline & $\mathrm{KJ}$ & $\mathrm{F}$ & 31 & 191,6 & 196,9 & 194,3 & 191,1 \\
\hline & LG & $\mathrm{F}$ & 21 & 185,7 & 188,4 & 187,1 & - \\
\hline & $\mathrm{MV}$ & $\mathrm{F}$ & 16 & 243,4 & 243,4 & 243,4 & - \\
\hline & RSC & $M$ & 22 & 268,1 & 256,5 & 262,3 & - \\
\hline & $\mathrm{RR}$ & $M$ & 40 & 533,3 & 536,1 & 534,7 & - \\
\hline & SS & $\mathrm{F}$ & 16 & 106,8 & 117,5 & 112,2 & - \\
\hline & VS & $\mathrm{F}$ & 22 & 359,5 & 363,1 & 361,3 & - \\
\hline MÉDIA $\pm D P$ & & & $29 \pm 11$ & $190,6 \pm 109,3$ & $186,9 \pm 111,4$ & $188,8 \pm 110,2$ & $162,5 \pm 73,9$ \\
\hline
\end{tabular}


Tabela 3 - Valores individuais de duas medições (T1 e T2) realizadas pelos avaliadores 1 e 2 e valores médios das áreas seccionais mínimas (ASM) faríngeas, expressos em $\mathrm{mm}^{2}$, do grupo fissura ( $\mathrm{GF}=30$ indivíduos com fissura labiopalatina), aferidos por tomografia computadorizada de feixe cônico.

\begin{tabular}{|c|c|c|c|c|c|c|c|}
\hline & & & & & Avaliador 1 & & Avaliador 2 \\
\hline Grupo & Nome & Sexo & Idade & $\begin{array}{c}\text { ASM } \\
\text { T1 }\end{array}$ & $\begin{array}{c}\text { ASM } \\
\text { T2 }\end{array}$ & $\begin{array}{c}\text { ASM } \\
\text { MÉDIA }\end{array}$ & ASM MÉDIA \\
\hline \multirow{30}{*}{$\begin{array}{c}\text { Com } \\
\text { Fissura } \\
(n=30)\end{array}$} & ASP & $\mathrm{M}$ & 18 & 212,9 & 174,4 & 193,7 & - \\
\hline & ASS & $M$ & 25 & 258,0 & 228,2 & 243,1 & - \\
\hline & AMC & $\mathrm{F}$ & 22 & 124,1 & 137,4 & 130,8 & 137,4 \\
\hline & ASB & $M$ & 25 & 115,0 & 105,2 & 110,1 & - \\
\hline & BMM & $M$ & 23 & 205,4 & 212,1 & 208,8 & - \\
\hline & $\mathrm{CR}$ & $M$ & 17 & 560,0 & 547,2 & 553,6 & - \\
\hline & CFS & $M$ & 19 & 188,8 & 195,3 & 192,1 & - \\
\hline & EOS & $F$ & 21 & 96,1 & 91,6 & 93,9 & - \\
\hline & EVS & $M$ & 30 & 42,2 & 40,4 & 41,3 & - \\
\hline & HEFS & $M$ & 19 & 331,7 & 329,0 & 330,4 & 312,3 \\
\hline & CRB & $\mathrm{F}$ & 23 & 170,4 & 158,6 & 164,5 & - \\
\hline & CPR & $\mathrm{F}$ & 36 & 48,6 & 46,2 & 47,4 & - \\
\hline & DS & $M$ & 18 & 163,1 & 160,3 & 161,7 & 160,2 \\
\hline & EMA & $M$ & 18 & 169,9 & 169,9 & 169,9 & - \\
\hline & JFA & $M$ & 17 & 145,9 & 139,1 & 142,5 & - \\
\hline & JMA & $\mathrm{F}$ & 24 & 125,0 & 124,0 & 124,5 & 126,3 \\
\hline & LS & $\mathrm{F}$ & 37 & 102,4 & 95,9 & 99,2 & - \\
\hline & MEA & $\mathrm{F}$ & 16 & 221,2 & 223,9 & 222,6 & - \\
\hline & PGA & $F$ & 27 & 284,4 & 239,1 & 261,8 & - \\
\hline & PRR & $M$ & 29 & 133,9 & 134,7 & 134,3 & - \\
\hline & PFV & $\mathrm{F}$ & 20 & 147,7 & 143,5 & 145,6 & - \\
\hline & RSR & $M$ & 19 & 129,4 & 131,8 & 130,6 & - \\
\hline & $\mathrm{RR}$ & $M$ & 21 & 190,7 & 166,3 & 178,5 & - \\
\hline & SJSF & $F$ & 25 & 88,1 & 88,1 & 88,1 & - \\
\hline & VSJ & $M$ & 24 & 147,1 & 135,3 & 141,2 & 141,3 \\
\hline & FGYX & $M$ & 21 & 46,0 & 47,7 & 46,9 & - \\
\hline & MSJ & $M$ & 25 & 116,6 & 110,4 & 113,5 & - \\
\hline & JPS & $F$ & 27 & 102,1 & 104,0 & 103,1 & - \\
\hline & AGTS & $M$ & 23 & 103,4 & 97,0 & 100,2 & - \\
\hline & BVO & $\mathrm{M}$ & 21 & 85,9 & 81,8 & 83,9 & - \\
\hline MÉDIA $\pm D P$ & & & $23 \pm 5$ & $161,9 \pm 101,3$ & $155,3 \pm 97,2$ & $158,6 \pm 99,1$ & $175,5 \pm 77,4$ \\
\hline
\end{tabular}




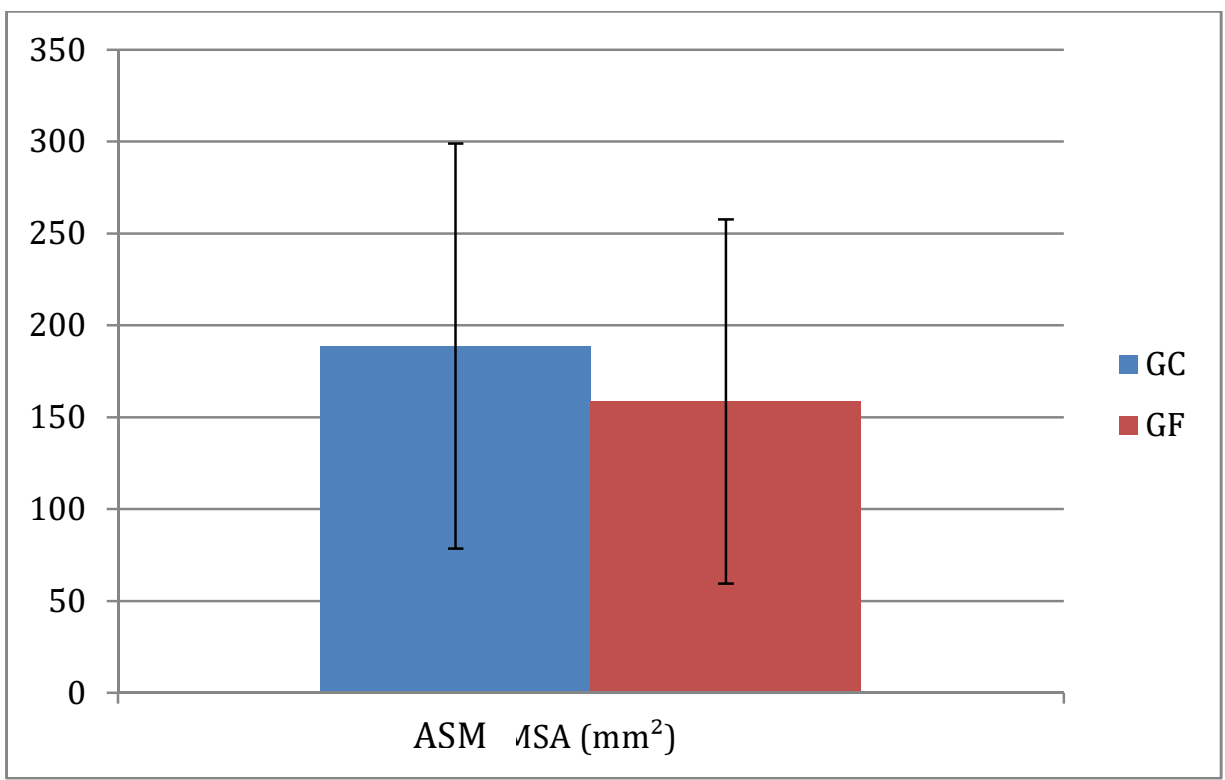

Figura 6 - Valores médios das áreas seccionais mínimas (ASM) faríngeas, expressos em $\mathrm{mm}^{2}$, do grupo controle (GC) e do grupo fissura (GF), aferidos por tomografia computadorizada de feixe cônico. 


\subsection{VOLUMES FARÍNGEOS}

$\mathrm{Na}$ Tabela 4 são mostrados os valores individuais e médios das duas medições (T1 e T2) do GC, realizadas pelos avaliadores 1 e 2 bem como os valores médios dos $\mathrm{V}$ faríngeos, expressos $\mathrm{em} \mathrm{cm}^{3}$. Os valores médios $( \pm \mathrm{DP})$ do $\mathrm{V}$, dos 30 indivíduos do GC, corresponderam a $26,9 \pm 9,6 \mathrm{~cm}^{3}$. Já, no GF, os valores corresponderam a $20,9 \pm 5,0 \mathrm{~cm}^{3}$, conforme mostra a Tabela 5. Valores significantemente menores foram encontrados no GF em relação ao GC. Estes resultados estão ilustrados na Figura 7.

Reunidos na Tabela 6, encontram-se os valores médios das ASMs e dos Vs dos GC e GF, para melhor visualização dos dados. Para fins de ilustração, na Figura 8 estão as imagens tridimensionais da ASM e do V faríngeos de dois indivíduos, a primeira do GC e a segunda do GF. 
Tabela 4 - Valores individuais de duas medições (T1 e T2) realizadas pelos avaliadores 1 e 2 e valores médios dos volumes $(V)$ faríngeos, expressos em $\mathrm{cm}^{3}$, do grupo controle $(\mathrm{GC}=30$ indivíduos sem fissura labiopalatina), aferidos por tomografia computadorizada de feixe cônico.

\begin{tabular}{|c|c|c|c|c|c|c|c|}
\hline \multirow[b]{2}{*}{ Grupo } & \multirow[b]{2}{*}{ Nome } & \multirow[b]{2}{*}{ Sexo } & \multirow[b]{2}{*}{ Idade } & \multicolumn{3}{|c|}{ Avaliador 1} & \multirow{2}{*}{$\begin{array}{c}\text { Avaliador } 2 \\
\text { V } \\
\text { MÉDIO }\end{array}$} \\
\hline & & & & $\begin{array}{l}\mathrm{V} \\
\mathrm{T} 1\end{array}$ & $\begin{array}{c}\mathrm{V} \\
\mathrm{T} 2 \\
\end{array}$ & $\begin{array}{c}\text { V } \\
\text { MÉDIO }\end{array}$ & \\
\hline \multirow{30}{*}{$\begin{array}{c}\text { Sem } \\
\text { Fissura } \\
(n=30)\end{array}$} & TGL & $F$ & 23 & 20,1 & 20,7 & 20,4 & - \\
\hline & JFD & $\mathrm{F}$ & 22 & 11,5 & 11,1 & 11,3 & 11,6 \\
\hline & ADN & $M$ & 44 & 16,3 & 16,7 & 16,5 & - \\
\hline & DIO & $M$ & 19 & 20,0 & 18,8 & 19,4 & - \\
\hline & GMO & $M$ & 13 & 20,2 & 19,5 & 19,9 & - \\
\hline & JCS & $M$ & 34 & 26,2 & 24,3 & 25,3 & - \\
\hline & LHS & $M$ & 30 & 29,3 & 26,2 & 27,8 & 27,3 \\
\hline & MRL & $M$ & 50 & 16,1 & 13,6 & 14,9 & - \\
\hline & VGO & $M$ & 54 & 21,9 & 21,7 & 21,8 & - \\
\hline & $\mathrm{AL}$ & $F$ & 20 & 27,1 & 26,8 & 27,0 & - \\
\hline & AS & $F$ & 36 & 27,6 & 26,3 & 27,0 & - \\
\hline & BT & $M$ & 21 & 44,2 & 41,2 & 42,7 & - \\
\hline & $\mathrm{CV}$ & $\mathrm{F}$ & 45 & 28,0 & 30,0 & 29,0 & 30,5 \\
\hline & DP & $\mathrm{F}$ & 24 & 23,5 & 22,6 & 23,1 & - \\
\hline & $\mathrm{FC}$ & $M$ & 47 & 17,2 & 16,6 & 16,9 & - \\
\hline & FJr & $M$ & 18 & 34,8 & 34,0 & 34,4 & - \\
\hline & FS & $M$ & 33 & 45,9 & 46,6 & 46,3 & - \\
\hline & GDP & $F$ & 19 & 19,9 & 18,8 & 19,4 & - \\
\hline & GLEL & $M$ & 25 & 37,4 & 38,5 & 38,0 & - \\
\hline & GRAL & $\mathrm{F}$ & 28 & 23,6 & 22,9 & 23,3 & - \\
\hline & ISF & $M$ & 39 & 28,7 & 26,9 & 27,8 & 28,4 \\
\hline & $\mathrm{JB}$ & $\mathrm{F}$ & 19 & 27,1 & 27,2 & 27,2 & - \\
\hline & JRR & $M$ & 33 & 30,0 & 30,2 & 30,1 & - \\
\hline & KJ & $\mathrm{F}$ & 31 & 40,0 & 39,9 & 40,0 & 40,3 \\
\hline & LG & $F$ & 21 & 17,1 & 16,9 & 17,0 & - \\
\hline & MV & $\mathrm{F}$ & 16 & 29,7 & 30,4 & 30,1 & - \\
\hline & RSC & $M$ & 22 & 32,6 & 31,6 & 32,1 & - \\
\hline & $\mathrm{RR}$ & $M$ & 40 & 50,8 & 51,9 & 51,4 & - \\
\hline & SS & $\mathrm{F}$ & 16 & 17,5 & 19,5 & 18,5 & - \\
\hline & VS & $\mathrm{F}$ & 22 & 27,0 & 28,7 & 27,9 & - \\
\hline MÉDIA $\pm D P$ & & & $29 \pm 11$ & $27,0 \pm 9,5$ & $26,7 \pm 9,7$ & $26,9 \pm 9,6$ & $27,62 \pm 9,23$ \\
\hline
\end{tabular}


Tabela 5 - Valores individuais de duas medições (T1 e T2) realizadas pelos avaliadores 1 e 2 e valores médios dos volumes (V) faríngeos, expressos em $\mathrm{cm}^{3}$, do grupo fissura ( $G F=30$ indivíduos com fissura labiopalatina), aferidos por tomografia computadorizada de feixe cônico.

\begin{tabular}{|c|c|c|c|c|c|c|c|}
\hline & \multirow[b]{2}{*}{ Nome } & \multirow[b]{2}{*}{ Sexo } & \multirow[b]{2}{*}{ Idade } & \multicolumn{3}{|c|}{ Avaliador 1} & \multirow{2}{*}{$\begin{array}{c}\text { Avaliador } 2 \\
\text { V } \\
\text { MÉDIO }\end{array}$} \\
\hline Grupo & & & & $\begin{array}{c}V \\
T 1\end{array}$ & $\begin{array}{c}\mathrm{V} \\
\mathrm{T} 2 \\
\end{array}$ & $\begin{array}{c}\text { V } \\
\text { MÉDIO }\end{array}$ & \\
\hline \multirow{30}{*}{$\begin{array}{c}\text { Com } \\
\text { Fissura } \\
(n=30)\end{array}$} & ASP & $M$ & 18 & 24,6 & 26,2 & 25,4 & - \\
\hline & ASS & $M$ & 25 & 27,7 & 26,0 & 26,9 & - \\
\hline & AMC & $\mathrm{F}$ & 22 & 15,7 & 17,2 & 16,5 & 16,7 \\
\hline & ASB & $M$ & 25 & 20,1 & 19,6 & 19,9 & - \\
\hline & BMM & $M$ & 23 & 24,4 & 28,7 & 26,6 & - \\
\hline & CR & $M$ & 17 & 35,2 & 35,9 & 35,6 & - \\
\hline & CFS & $M$ & 19 & 26,2 & 25,9 & 26,1 & - \\
\hline & EOS & $\mathrm{F}$ & 21 & 16,2 & 15,7 & 16,0 & - \\
\hline & EVS & $M$ & 30 & 15,4 & 14,1 & 14,8 & - \\
\hline & HEFS & $M$ & 19 & 23,4 & 24,5 & 24,0 & 24,4 \\
\hline & CRB & $\mathrm{F}$ & 23 & 16,5 & 16,0 & 16,3 & - \\
\hline & CPR & $\mathrm{F}$ & 36 & 17,5 & 17,6 & 17,6 & - \\
\hline & DS & $M$ & 18 & 22,3 & 21,6 & 22,0 & 21,1 \\
\hline & EMA & $M$ & 18 & 23,9 & 24,0 & 24,0 & - \\
\hline & JFA & $M$ & 17 & 21,4 & 20,9 & 21,2 & - \\
\hline & JMA & $F$ & 24 & 20,3 & 23,5 & 21,9 & 23,1 \\
\hline & LS & $\mathrm{F}$ & 37 & 22,5 & 21,5 & 22,0 & - \\
\hline & MESA & $F$ & 16 & 26,2 & 26,7 & 26,5 & - \\
\hline & PGA & $F$ & 27 & 23,8 & 21,7 & 22,8 & - \\
\hline & PRR & $M$ & 29 & 22,2 & 22,9 & 22,6 & -- \\
\hline & PFV & $F$ & 20 & 16,7 & 16,6 & 16,7 & - \\
\hline & RSR & $M$ & 19 & 24,0 & 25,2 & 24,6 & -- \\
\hline & $\mathrm{RR}$ & $M$ & 21 & 18,5 & 16,5 & 17,5 & - \\
\hline & SJSF & $\mathrm{F}$ & 25 & 12,3 & 12,4 & 12,4 & - \\
\hline & VSJ & $M$ & 24 & 20,7 & 19,4 & 20,1 & 19,5 \\
\hline & FGYX & $M$ & 21 & 19,9 & 20,8 & 20,4 & - \\
\hline & MSJ & $M$ & 25 & 21,5 & 21,9 & 21,7 & -- \\
\hline & JPS & $\mathrm{F}$ & 27 & 15,3 & 14,9 & 15,1 & - \\
\hline & AGTS & $M$ & 23 & 13,4 & 12,4 & 12,9 & - \\
\hline & BVO & $\mathrm{M}$ & 21 & 19,0 & 19,0 & 19,0 & - \\
\hline MÉDIA $\pm D P$ & & & $23 \pm 5$ & $20,0 \pm 4,8$ & $21,0 \pm 5,3$ & $20,9 \pm 5,0$ & $20,96 \pm 3,02$ \\
\hline
\end{tabular}




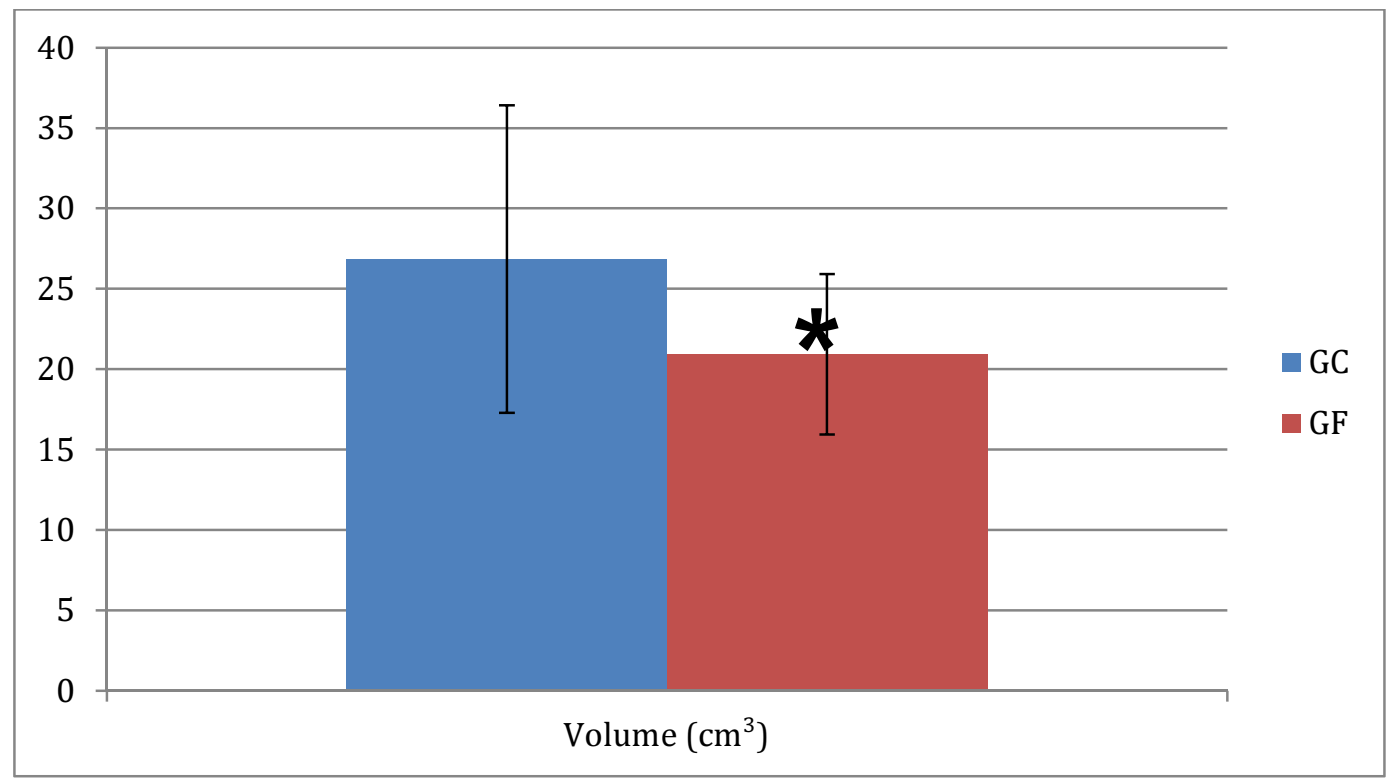

Figura 7 - Valores médios dos volumes $(V)$ faríngeos, expressos em $\mathrm{cm}^{3}$, do grupo controle (GC) e do grupo fissura (GF), aferidos por tomografia computadorizada de feixe cônico. $O$ asterisco índia diferença estatisticamente significante entre os grupos (GC vs GF). 
Tabela 6 - Valores médios das áreas seccionais mínimas (ASM) e dos volumes (V) faríngeos, expressos em $\mathrm{mm}^{2} \mathrm{e} \mathrm{cm}^{3}$, respectivamente, do grupo controle (GC) e do grupo fissura (GF), aferidos por tomografia computadorizada de feixe cônico.

\section{ASM médio}

$\left(\mathbf{m m}^{2}\right)$

$188,8 \pm 110,2$

$158,6 \pm 99,1$

\section{V médio}

$\left(\mathrm{cm}^{3}\right)$

$26,9 \pm 9,6$

${ }^{*} p=0,004$
GF

GC 


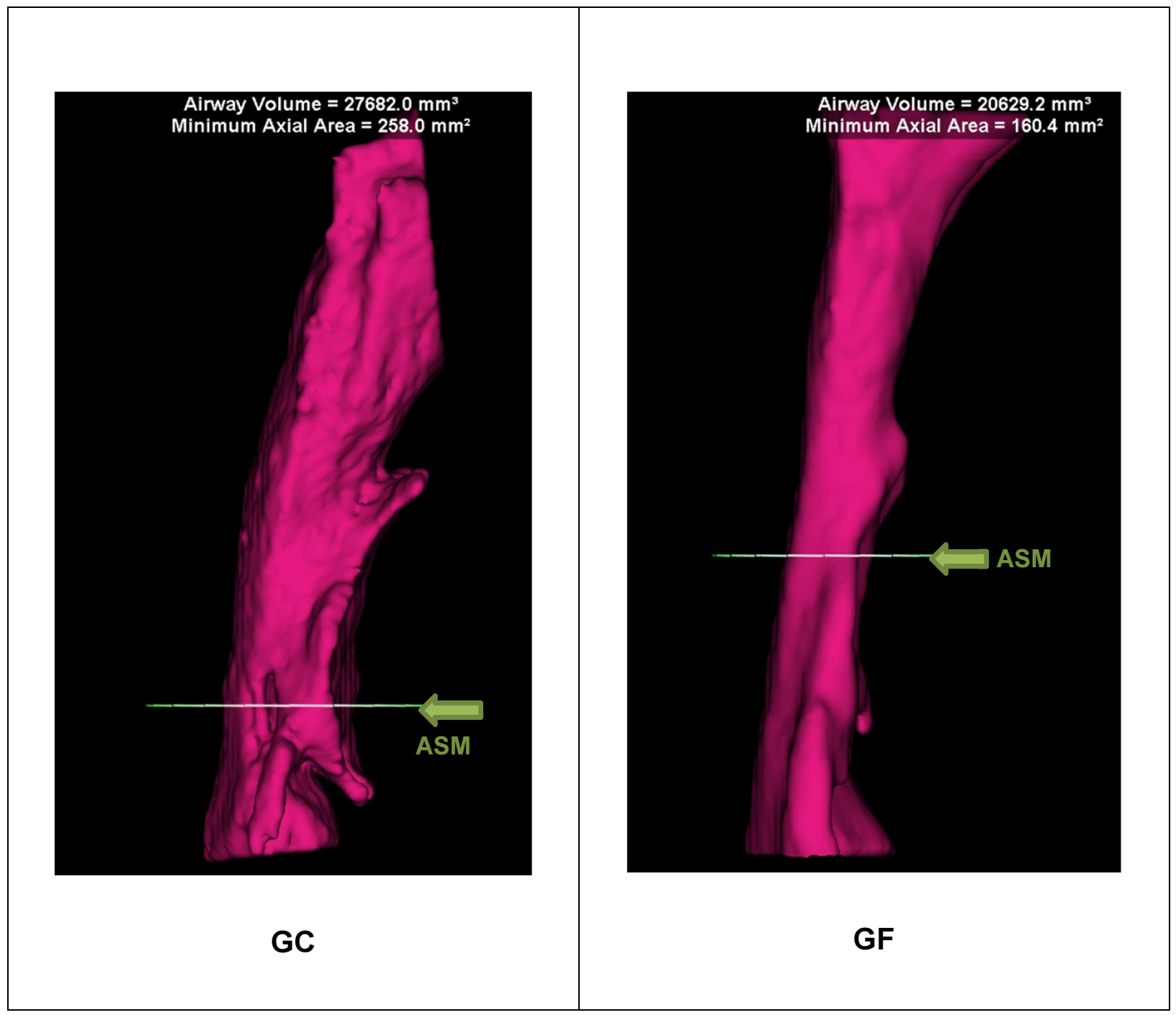

Figura 8 - Imagens tridimensionais da área seccional mínima (ASM) e dos volumes faríngeos. A primeira de um indivíduo do grupo controle (GC) e a segunda de um indivíduo do grupo com fissura (GF). 



\subsection{CORRELAÇÃO ENTRE VARIÁVEIS}

A correlação entre as variáveis $A S M$ e $V, e, A S M$ e idade, nos grupos GC e GF, foi aferida pelo Coeficiente de correlação de Pearson. Valores de $p<0.05$ foram considerados significantes.

Conforme ilustram as Figuras 9 e 10, constatou-se forte correlação positiva entre as variáveis ASM e V, nos grupos GC e GF $(p<0.001)$. Isto significa que, na amostra avaliada, quanto maior é o $\mathrm{V}$, maior é a $\mathrm{ASM}$.

Já, para as variáveis ASM e idade, constatou-se forte correlação negativa, apenas no grupo GF ( $p=0.017)$. Em outras palavras, enquanto uma variável tende a aumentar (Idade) a outra variável (ASM) tende a diminuir. A figura 11 ilustra estes dados. 


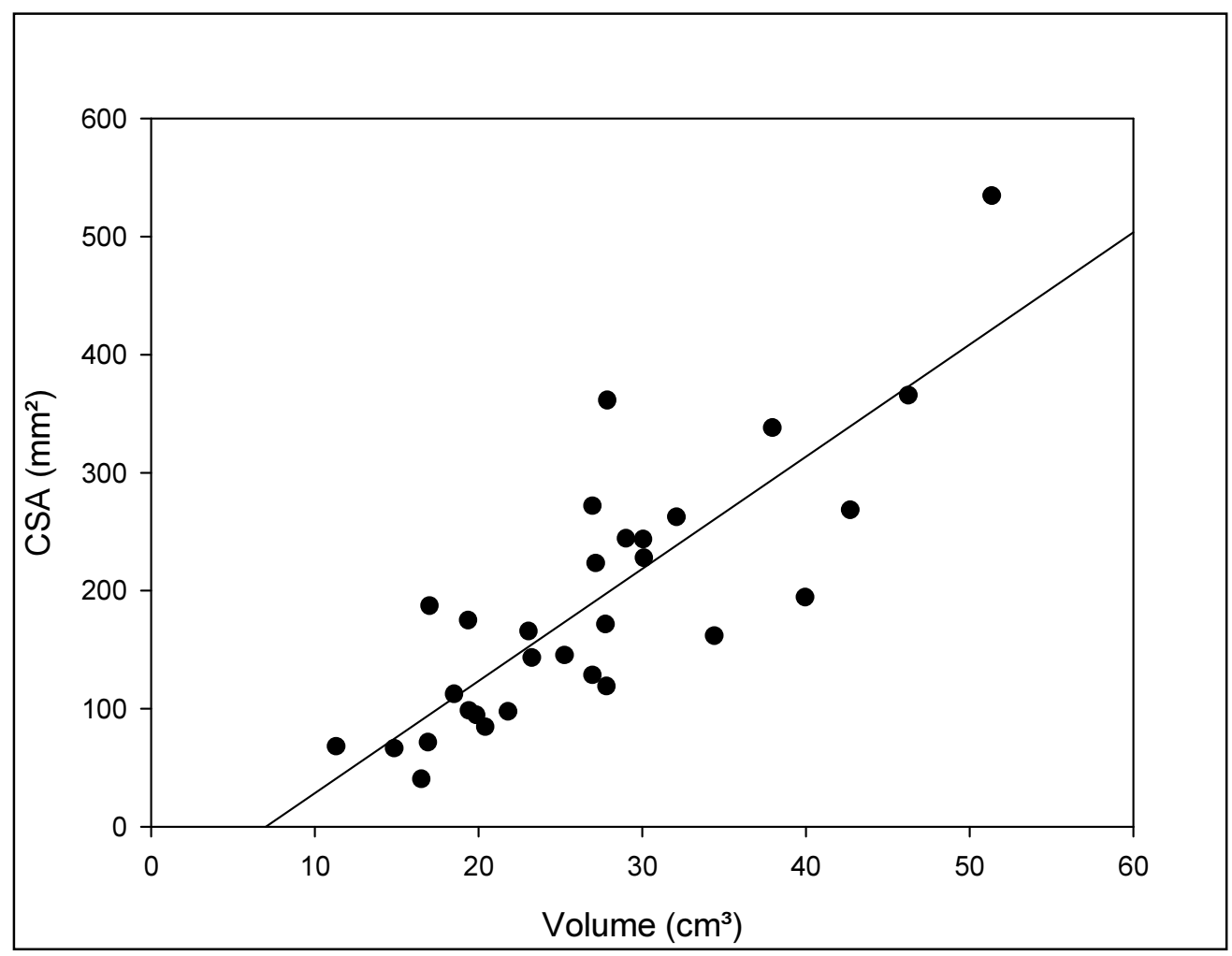

Figura 9 - Gráfico de correlação das variáveis ASM e V, no grupo GC.

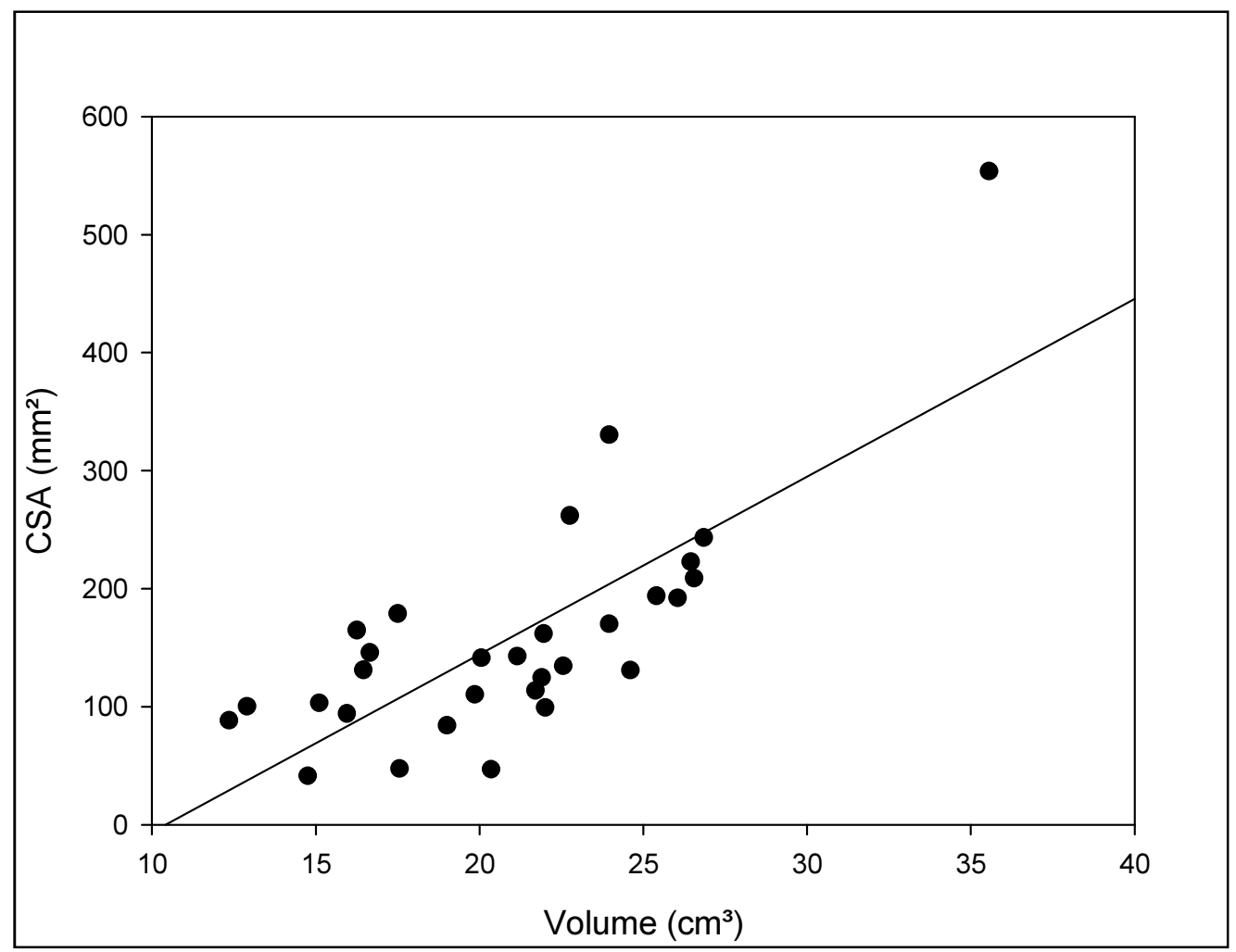

Figura 10 - Gráfico de correlação das variáveis ASM e V, no grupo GF. 


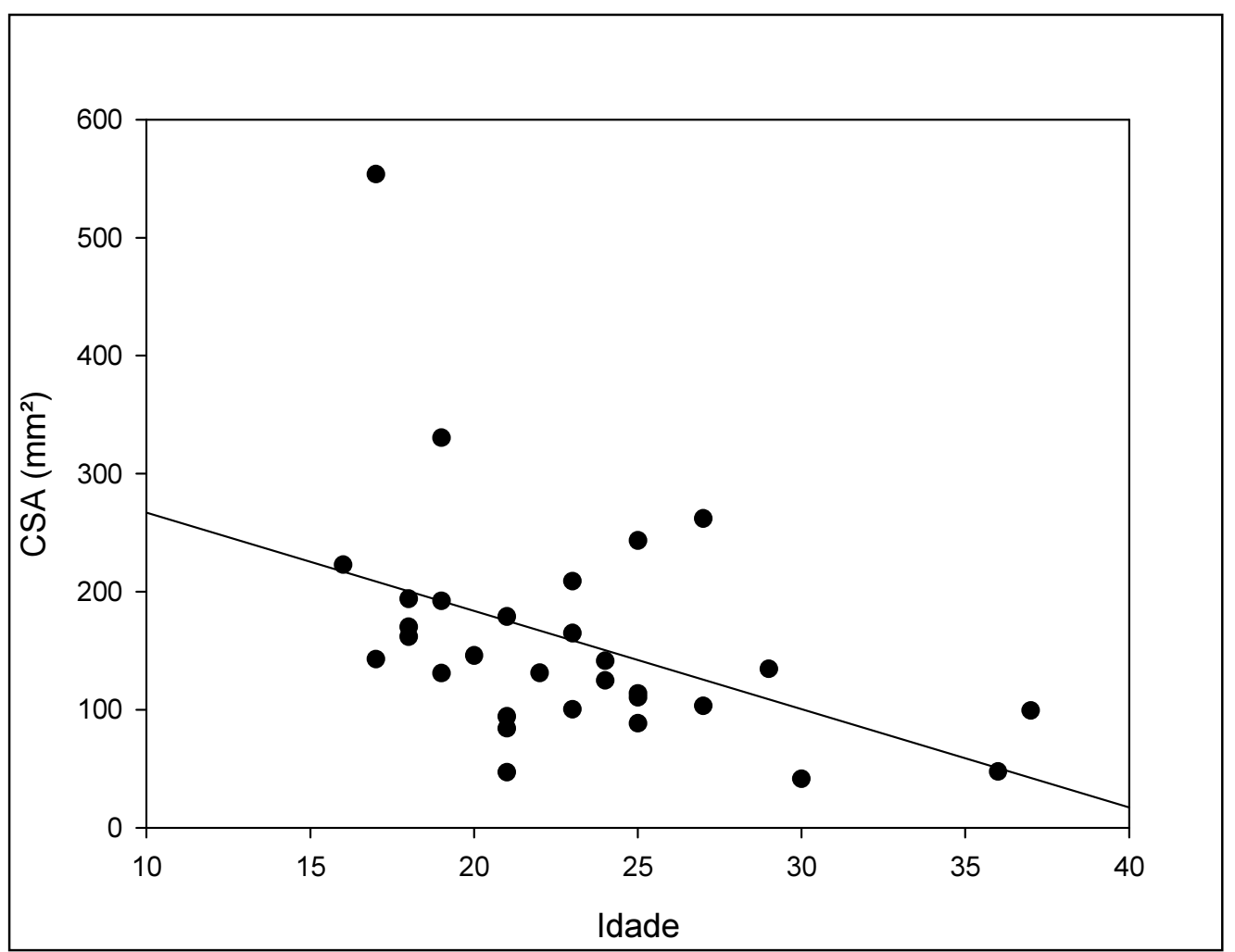

Figura 11 - Gráfico de correlação das variáveis ASM e idade, no grupo GF. 



\section{DISCUSSÃO}





\section{DISCUSSÃO}

Estudos do grupo de pesquisa do Laboratório de Fisiologia do HRAC/USP têm demonstrado que o nariz do paciente com fissura apresenta as dimensões internas reduzidas em decorrência, principalmente, dos efeitos deletérios das cirurgias plásticas primárias, queiloplastia e palatoplastia, sobre complexo maxilofacial, restringindo seu crescimento $e$, consequentemente, de todas as estruturas a ele relacionadas, em especial, a cavidade nasal (Fukushiro e Trindade 2005; Trindade, Bertier, Sampaio-Teixeira 2009 e Trindade et al, 2010). De acordo com Bertier e Trindade (2007), as anormalidades anatômicas destas estruturas fazem com que as vias aéreas estejam comprometidas funcionalmente em $60 \%$ dos pacientes com fissura.

Todavia, pouco se sabe sobre o efeito das fissuras e de seus procedimentos reabilitadores sobre a faringe. Alguns autores afirmam que o espaço faríngeo dos pacientes com fissura apresenta-se volumetricamente maior que o de pacientes sem fissura (Aras, Olmez e Dogan 2012; Olmez, Aras e Dogan 2014, Xu et al, 2013). Já um segundo grupo de autores (Celikoglu et al 2014; Diwakar et al 2014) afirma que o espaço aéreo posterior dos indivíduos com fissura é volumetricamente menor que o de sujeitos sem fissura. Por fim, há um terceiro grupo de autores que considera que não há diferença dimensional entre o espaço aéreo posterior dos indivíduos com e sem fissura (Pimenta et al 2014, Cheung e Oberoi 2012). Por este motivo, foi objetivo primário deste estudo caracterizar tridimensionalmente o espaço aéreo faríngeo do paciente com fissura labiopalatina unilateral. 
Para se fins de padronização da amostra do presente estudo adotou-se como critério de inclusão sujeitos com discrepância maxilomandibular caracterizada por relação oclusal classe III de Angle, apenas pacientes após o término do crescimento e desenvolvimento facial, para ambos os grupos. Isto porque, é condição bastante frequente no indivíduo com fissura a presença desta discrepância, mais uma vez, em decorrência dos efeitos restritivos ao crescimento maxilar que as cirurgias reabilitadoras impõem sobre a face destes indivíduos.

Já, o motivo de serem selecionados para este estudo apenas pacientes com fissura unilateral se justifica por ser esta o tipo de fissura mais frequente, $30 \%$ dos casos (Silva Filho e Freitas 2007), o que torna este grupo o de maior interesse clínico. Contudo, a análise de tomografias de pacientes com outros tipos de fissura já está em andamento.

Outro detalhe metodológico relevante adotado neste estudo refere-se à confecção do polígono que delimita a área de interesse. Via de regra, os estudos que avaliam volumetricamente a via aérea por meio de imagens, utilizam como um dos pontos de referência a espinha nasal posterior. No entanto, devido à presença da fissura, foi grande a dificuldade em encontrar este ponto anatômico no GF. Portanto, visando a reprodutibilidade do método, os avaliadores optaram por traçar uma linha reta que ligava a borda anterosuperior da sela pituitária (ponto $S^{\prime}$ ) e o limite anteroinferior do osso hióide (ponto H) abrangendo ao máximo a nasofaringe. Este polígono com estas características foi adotado em ambos os grupos para fins de padronização do método.

Seguindo estes critérios metodológicos foram obtidos importantes resultados. Quanto à área seccional mínima faríngea, conforme era esperado, esta variável 
apresentou-se menor no grupo de indivíduos com fissura, apesar deste dado não ter sido considerado significante. Isto significa que e o paciente com fissura apresenta, em determinada altura da faringe, uma área mais constrita, mais estreita, quando comparada à dos sujeitos sem fissura.

Esta contrição representa fator de risco para apneia neste grupo de indivíduos, conforme demonstrou trabalho também desenvolvido pela equipe do Laboratório de Fisiologia do HRAC/USP no qual se utilizou a polissonografia para aferição do índice de apneia e hipopneia (IAH) e que recentemente foi aceito para publicação (Campos et al 2015). Este estudo demonstrou que sujeitos com fissura labiopalatina, com ou sem retalho faríngeo, apresentam desordens respiratórias do sono em proporção clinicamente significativa, possivelmente relacionadas a alterações anátomofuncionais das vias aéreas superiores, congênitas ou secundárias às palatoplastias.

Outro estudo de nosso Laboratório (Silva Junior 2014) demonstrou, por meio de questionários, que parcela considerável (62\%) dos indivíduos adultos jovens com fissura labiopalatina, população esta com a mesma faixa etária da amostra do presente estudo, apresenta qualidade do sono ruim e que um $33 \%$ apresenta alto risco para apneia do sono, dados estes relacionados à época, à obesidade e à presença de retalho faríngeo. Outro fator que agora pode justificar este resultado é existência de uma faringe volumetricamente menor nestes pacientes, mesmo na ausência do retalho faríngeo.

Valores de corte da ASM que favoreçam a colapsabilidade da faringe durante o sono, levando o indivíduo a ser considerado como de alto risco para apneia, não foram encontrados na literatura. Contudo, estudos como o de Tang et al (2012) têm 
demonstrado que a região retropalatal, ou seja, a orofaringe, constitui o principal sítio de obstrução em pacientes com a síndrome da apneia e hipopneia do sono (SAHOS). Estudo que investiga o nível da localização das ASMs em indivíduos com e sem fissura terá início em futuro próximo pelo nosso grupo de pesquisa. À exemplo do que mostra a Figura 8, nota-se que a ASM pode estar localizada em diferentes regiões da faringe. A primeira imagem, por exemplo, mostra a ASM localizada na hipofaringe e a segunda na orofaringe. Este estudo constitui o primeiro passo para a determinação de valores de corte críticos para a ASM, dado este a ser aferido por tomografia e polissonografia.

Quanto ao volume faríngeo, à semelhança da ASM, esta variável também se mostrou reduzida no grupo de indivíduos com fissura, em relação ao grupo sem fissura. Este dado foi considerado estatisticamente significante.

Estes dados são contrários aos obtidos por Pimenta et al (2014) do Centro Craniofacial da Universidade da Carolina do Norte, grupo cientificamente ligado ao Laboratório de Fisiologia do HRAC/USP. Estes autores constataram, por meio de TCFC, que não há diferença no volume da nasofaringe de pacientes com fissura e sem fissura. Ressalta-se que os autores avaliaram apenas um segmento da faringe e não todo o seu volume, daí uma possível explicação para a divergência dos resultados.

Todavia, os resultados do presente resultado vão de acordo com os achados de Celikoglu et al (2014) e Diwakar et al. (2014) que obtiveram valores de volume da via aérea substancialmente menores no grupo de pacientes com fissura em relação ao grupo sem fissura. Contudo, nestes estudos, alguns dos pacientes ainda estavam em fase de crescimento. Ressalta-se aqui um ponto forte do presente estudo no qual 
foram incluídos apenas indivíduos que atingiram o término o crescimento. Isto significa que as áreas e volumes faríngeos da população estudada são dimensionalmente estáveis.

Com o propósito de se estabelecer uma possível associação entre as variáveis estudadas, constatou-se forte correlação positiva entre ASM e V, em ambos os grupos. Este resultado nos parece óbvio e, clinicamente, significa que, na amostra avaliada, quanto maior é o volume do espaço aéreo faríngeo de um paciente, independentemente de estar ou não associado à fissura, maior é a área seccional mínima faríngea. O inverso também é verdadeiro.

Foram correlacionadas também as variáveis ASM e idade. Era nossa hipótese que, em indivíduos adultos, que já cessaram o crescimento esquelético-facial, quanto maior a idade, menor a área faríngea. Isto baseado no estudo epidemiológico de Tufik et al (2010), no qual os autores encontraram aproximadamente $7 \%$ de indivíduos adultos jovens (20-29 anos) com SAHOS ao passo que, em indivíduos de meia idade (40-49 anos), a prevalência aumentou significantemente para $49 \%$. Uma das possíveis justificativas para o aumento da prevalência da SAHOS com o aumento da idade é justamente a diminuição da área faríngea em decorrência do sobrepeso que acompanha frequentemente o aumento da idade. Isto se torna evidente ao se analisar individualmente dois pacientes do GC: 1)paciente VGO, 54 anos, $\left.A S M=97,4 \mathrm{~mm}^{2}, \mathrm{e}, 2\right)$ paciente $M V, 16$ anos, com $A S M=243,4 \mathrm{~mm}^{2}$. Contudo, a análise estatística confirmou esta hipótese apenas no grupo de indivíduos com fissura labiopalatina. Talvez porque o desvio padrão das variáveis idade e ASM média no GC tenham sido maiores. 
Fatores como a realização prévia de cirurgias de adenoidectomia, amidalectomia e expansão cirúrgica de maxila, além da obesidade, que podem ter influencia nas dimensões do espaço aéreo faríngeo, não puderam ser controladas uma vez que este foi um estudo no qual se analisou tomografias previamente realizadas para fins de planejamento cirúrgicos e, nem sempre, no prontuário do paciente estavam registrados estes dados. Diwakar et al (2014) destacam o grande volume ocupado pela adenoides frequentemente hipertróficas nos pacientes com fissura e mencionam a dificuldade de se padronizar estas variáveis. Da mesma forma Tufik et al (2010) confere à obesidade um papel importante no desenvolvimento e manutenção da SAHOS.

Estudo que avalie as vias aéreas superiores por meio de imagens 3D em indivíduos com morfologias craniofaciais distintas, como as classes I e II de Angle, nos sujeitos com e sem fissura, deve ser realizado e constitui a continuação este trabalho. Além disso, esta metodologia deve ser aplicada também para diferentes tipos de fissura, em especial as bilaterais completas, cujas alterações anatomofuncionais manifestam-se de forma mais intensa, inclusive para as vias aéreas.

O foco destes estudos, além de caracterizar tridimensionalmente a faringe dos indivíduos e seus diferentes padrões faciais e oclusais também deverá estar em dois outros aspectos: 1) na investigação dos volumes e áreas seccionais das cavidades nasais, que também constituem fator crítico para apneia, e, principalmente, os efeitos das cirurgias ortognáticas de avanço maxilomandibular sobre o espaço aéreo destes sujeitos. 
Estudos como o de Hernández-Alfaro et al. (2011) indicam que, neste último caso, ocorra um aumento clinicamente significativo das vias aéreas, evidenciandose, assim, uma indicação a mais deste tipo de procedimento reabilitados para os pacientes portadores de más-oclusões, independentemente da presença ou não das fissuras. Como mencionado anteriormente, estudos que avaliam as alterações dimensionais das vias aéreas superiores após cirurgia ortognática em pacientes com fissuras labiopalatinas não foram encontrados.

Assim, o principal achado do presente estudo confirma a hipótese inicial de que o espaço aéreo posterior dos indivíduos com fissura está diminuído, tanto em volume como, principalmente, a área seccional mínima. Os autores consideram a ASM estreita como um dos principais fatores risco para apneia do sono, principalmente quando associada à obesidade. Vale ressaltar que este fator não foi controlado neste estudo. Entende-se, ainda, que de nada adiante um sujeito possuir uma faringe volumosa se esta via aérea possuir ao longo de seu comprimento uma área de grande constrição. Esta área reduzida já é suficiente para induzir o risco para apneia. Em outras palavras, acredita-se que, potencialmente, este indivíduo possui risco similar àquele que possui uma faringe estrita em todo o seu trajeto. Como dito anteriormente, não existe na literatura trabalhos que indiquem um valor de corte da ASM como sendo de risco para apneia. Planeja-se em futuro próximo, desenvolver estudos em nosso laboratório que determinem este valor, por meio de tomografia e polissonografia.

Em suma, os resultados obtidos demonstram que a faringe dos indivíduos com fissura labiopalatina apresenta-se volumetricamente menor que a de indivíduos sem fissura, o que levaria a uma maior colapsabilidade da faringe, e, consequentemente, maior risco para apneia obstrutiva do sono. 

6 CONCLUSÕES 



\section{CONCLUSÕES}

Frente aos resultados obtidos, com o uso tomografia computadorizada de feixe cônico, é possível concluir que:

1) A via aérea do paciente que possui perfil caracterizado por discrepância dentofacial esquelética, classe III de Angle, se encontra diminuída volumetricamente quando associada à fissura labiopalatina unilateral completa, em relação aos pacientes portadores dessas mesmas características sem fissura labiopalatina;

2) Apesar de estatisticamente não significante, os indivíduos com fissura palatina unilateral completa e discrepância dentofacial esquelética, classe III de Angle apresentam as áreas seccionais mínimas faríngeas menores que aos pacientes portadores dessas mesmas características sem fissura labiopalatina;

3) Quanto maior o volume do espaço aéreo faríngeo de um paciente, independentemente de estar associado a fissura labiopalatina ou não, maior será o valor da área seccional mínima faríngea do mesmo;

4) Nos indivíduos com fissura labiopalatina unilateral completa, conforme a idade avança, o valor da área seccional mínima tende a diminuir. 



\section{REFERÊNCIAS}





\section{REFERÊNCIAS}

Aiello, CA. Efeitos ortopédicos e ortodônticos da tração reversa maxilar em pacientes com fissura transforame incisivo unilateral. [dissertação]. Bauru: Hospital de Reabilitação de Anomalias Craniofaciais, Universidade de São Paulo; 2005

Aras I, Olmez S, Dogan S. Comparative evaluation of nasopharyngeal airways of unilateral cleft lip and palate patients using three-dimensional and two-dimensional methods. Cleft Palate Craniofac J. 2012;49(6):e75-81.

Bertier CE, Trindade IEK. Deformidades nasais: avaliação e tratamento cirúrgico In: Trindade IEK, Silva Filho OG, organizadores. Fissuras labiopalatinas: uma abordagem interdisciplinar. São Paulo, SP: Santos, 2007. p. 87-107.

Campos LD, Trindade-Suedam IK, Sampaio-Teixeira ACM, Yamashita RP, Lauris JR, Lorenzi-Filho G, Trindade IEK. Obstructive sleep apnea following pharyngeal flap surgery for velopharyngeal insufficiency: a prospective polysomnographic and aerodynamic study in middle-aged adults. Cleft Palate Craniofac J. 2012 (in press)

Cate, ART. Embriologia da cabeça, face e cavidade oral. In: Histologia bucal: desenvolvimento, estrutura e função. 5 ed. Rio de Janeiro: Guanabara Koogan. $2001 ; 3: 25-49$.

Celikoglu M, Buyuk SK, Sekerci AE, Ucar FI, Cantekin K. Three-dimensional evaluation of the pharyngeal airway volumes in patients affected by unilateral cleft lip and palate. American journal of orthodontics and dentofacial orthopedics : official publication of the American Association of Orthodontists, its constituent societies, and the American Board of Orthodontics. 2014;145(6):780-6.

Cheung T, Oberoi S. Three dimensional assessment of the pharyngeal airway in individuals with non-syndromic cleft lip and palate. PloS one. 2012;7(8):e43405.

Claudino LV, Mattos CT, Ruellas AC, Sant' Anna EF. Pharyngeal airway characterization in adolescents related to facial skeletal pattern: a preliminary study. American journal of orthodontics and dentofacial orthopedics : official publication of the American Association of Orthodontists, its constituent societies, and the American Board of Orthodontics. 2013;143(6):799-809.

Cohen MM Jr. Etiology and pathogenesis of orofacial clefting. Oral Maxillofac Surg Clin North Am. 2000; 12(3):379-97. 
Diewert VM. A morphometric analysis of craniofacial growth and changes in spatial relations during secondary palatal development in human embryos and fetuses. Am J Anat. 1983; 167(4):495-522.

Diwakar R, Sidhu MS, Jain S, Grover S, Prabhakar M. Three-Dimensional Evaluation of Pharyngeal Airway in Complete Unilateral Cleft Individuals and Normally Growing Individuals Using Cone Beam Computed Tomography. Cleft Palate Craniofac J.

2014.

El H, Palomo JM. Airway volume for different dentofacial skeletal patterns. American journal of orthodontics and dentofacial orthopedics: official publication of the American Association of Orthodontists, its constituent societies, and the American Board of Orthodontics. 2011;139(6):e511-21.

El H, Palomo JM. An airway study of different maxillary and mandibular sagittal positions. European journal of orthodontics. 2013;35(2):262-70.

Fleiss, J.L. (1999) Analysis of Covariance and the Study of Change, En J.L. Fleiss (Ed.). The Design and Analysis of Clinical Experiments. Hoboken, NJ, USA: John Wiley \& Sons, Inc.

Fukushiro AP, Trindade IEK. Nasal airway dimensions of adults with cleft lip and palate: diferences among cleft types. Cleft Palate-Craniofac J. 2005;42(4):396-402.

Gorlin RJ, Cohen MMJr, Levin LS. Syndromes of the head and neck. 3 ed. New York: Oxford University Press, 1990.

Grauer D, Cevidanes LS, Styner MA, Ackerman JL, Proffit WR. Pharyngeal airway volume and shape from cone-beam computed tomography: relationship to facial morphology. American journal of orthodontics and dentofacial orthopedics : official publication of the American Association of Orthodontists, its constituent societies, and the American Board of Orthodontics. 2009;136(6):805-14.

Hamada $Y$, Kondoh T, Noguchi $K$, lino $M$, Isono $H$, Ishii $H$, Mishima A, Kobayashi $K$, Seto K. Application of limited cone beam computed tomography to clinical assessment of alveolar bone grafting: a preliminary report. Cleft Palate Craniofac J. 2005;42(2):128-37.

Hatcher DC. Cone beam computed tomography: craniofacial and airway analysis. Dent Clin North Am. 2012 Apr;56(2):343-57.

Hernández-Alfaro F, Guijarro-Martínez R, Mareque-Bueno J. Effect of mono-and bimaxillary advancement on pharyngeal airway volume: cone-beam computed tomography evaluation. J Oral Maxillofac Surg. 2011 Nov;69(11):e395-400. 
Kim YJ, Hong JS, Hwang YI, Park YH. Three-dimensional analysis of pharyngeal airway in preadolescent children with different anteroposterior skeletal patterns. American journal of orthodontics and dentofacial orthopedics : official publication of the American Association of Orthodontists, its constituent societies, and the American Board of Orthodontics. 2010;137(3):306 e1-11; discussion -7.

Kondo S, Schutte BC, Richardson RJ, Bjork BC, Knight AS, Watanabe Y, et al. Mutations in IRF6 cause Van der Woude and popliteal pterygium syndromes. Nat Genet. 2002;32(2):285-9.

Lee JY, Kim YI, Hwang DS, Park SB. Effect of maxillary setback movement on upper airway in patients with class III skeletal deformities: cone beam computed tomographic evaluation. J Craniofac Surg. 2013 Mar;24(2):387-91.

Lee $\mathrm{Y}$, Chun YS, Kang N, Kim M. Volumetric changes in the upper airway after bimaxillary surgery for skeletal class III malocclusions: a case series study using 3dimensional cone-beam computed tomography. J Oral Maxillofac Surg. 2012 Dec;70(12):2867-75.

Ludlow JB, Davies-Ludlow LE, Brooks SL, Howerton WB. Dosimetry of 3 CBCT devices for oral and maxillofacial radiology: CB Mercuray, NewTom 3G and i-CAT. Dentomaxillofac Radiol. 2006;35(4):219-26.

Mars M, Plint DA, Houston WJ, Bergland O, Semb G. The Goslon Yardstick: a new system of assessing dental arch relationships in children with unilateral clefts of the lip and palate. Cleft Palate J. 1987;24(4):314-22.

Nagem Filho H, Morais N, Rocha RGF. Contribuição para o estudo pda prevalência das malformações congênitas labiopalatinas na população escolar de Bauru. Rev Fac Odonto São Paulo. 1968;7:111-28.

Oberoi S, Chigurupati R, Gill P, Hoffman WY, Vargervik K. Volumetric assessment of secondary alveolar bone grafting using cone beam computed tomography. Cleft Palate Craniofac J. 2009 Sep;46(5):503-11.

Ogawa T, Enciso R, Shintaku WH, Clark GT. Evaluation of cross-section airway configuration of obstructive sleep apnea. Oral Surg Oral Med Oral Pathol Oral Radiol Endod. 2007 Jan;103(1):102-8.

Olmez, S.; Aras, I.; Dogan, S. Nasopharyngeal Airway Volume for Different GOSLON Scores in Patient With Unilateral Cleft Lip and Palate. Cleft Palate Craniofac J, Dec 222014. 
Pimenta LA, de Rezende Barbosa GL, Pretti H, Emodi O, van Aalst J, Rossouw PE, et al. Three-dimensional evaluation of nasopharyngeal airways of unilateral cleft lip and palate patients. The Laryngoscope. 2014.

Shaw W, Semb G. In: Trindade IEK, Silva Fllho OG, editors. Fissuras Labiopalatinas: uma abordagem interdisciplinar. São Paulo: Editora Santos; 2007. p.1-5.

Silva Filho OG. Crescimento Facial. In: Trindade IEK, Silva Filho OG, organizadores. Fissuras labiopalatinas: uma abordagem interdisciplinar. São Paulo: Editora Santos; 2007. p. 173-198.

Silva Filho OG, Ferrari Jr FM, Rocha DL, Freitas JAS. Classificação das fissuras lábio-palatais: breve histórico, considerações clínicas e sugestão de modificação. Rev Bras Cir. 1992;82(2):59-65.

Silva Filho OG, Ferrari Júnior FM, Capelozza Filho L, Albuquerque MV. Enxerto ósseo alveolar em pacientes fissurados: realidade e perspectiva. Ortodontia. 1995;28(1):34-45.

Silva Filho OG, Freitas JAS, Ozawa TO, Trindade-Suedam IK. Fissuras labiopalatinas: fundamentos terapêuticos. In: Melega JM, editor. Cirurgia plástica - os princípios e a atualidade. Rio de Janeiro: Guanabara Koogan; 2011. p. 285-304.

Silva Filho OG, Freitas JAS. Caracterização morfológica e origem embriológica. In: Trindade IEK, Silva Filho OG, organizadores. Fissuras labiopalatinas: uma abordagem interdisciplinar. São Paulo: Editora Santos; 2007. p. 17-49.

Silva Filho OG, Teles SG, Ozawa TO, Capelozza Filho L. Secondary bone graft and eruption of the permanent canine in patients with alveolar clefts: literature review and case report. Angle Orthod. 2000;70(2):174-8.

Silva Junior W. Qualidade do sono de adultos jovens com fissura labiopalatina [tese]. Bauru: Hospital de Reabilitação de Anomalias Craniofaciais, Universidade de São Paulo; 2013.

Smahel Z, Müllerová I. Nasopharyngeal characteristics in children with cleft lip and palate. Cleft Palate Craniofac J. 1992 May;29(3):282-6.

Sperber GH. Craniofacial embryology. 4th ed. London: Wright;1989:7-57. 
Spina V, Psillakis JM, Lapa FS, Ferreira MC. Classificação das Fissuras Lábiopalatinas. Sugestão de modificação. Rev Hosp Clín Fac Med São Paulo. 1972;27:56.

Tang SC, Lam B, Lam JC, Chan CK, Chow CC, Ho YW, et al. Impact of nephrotic edema of the lower limbs on obstructive sleep apnea: gathering a unifying concept for the pathogenetic role of nocturnal rostral fluid shift. Nephrology, dialysis, transplantation : official publication of the European Dialysis and Transplant Association - European Renal Association. 2012;27(7):2788-94.

Trindade IEK, Bertier CE, Sampaio-Teixeira ACM. Objective assessment of internal nasal dimensions and speech resonance in individuals with repaired unilateral cleft lip and palate after rhinoseptoplasty. J Craniofac Surg. 2009;20(2):308-14.

Trindade IEK, Castilho RL, Sampaio-Teixeira ACM, Trindade-Suedam IK, Silva Filho OG. Effects of orthopedic rapid maxillary expansion on internal nasal dimensions in children with cleft lip and palate assessed by acoustic rhinometry. J Craniofac Surg. 2010;21(2):306-11.

Tufik S, Santos-Silva R, Taddei JA, Bittencourt LR. Obstructive sleep apnea syndrome in the Sao Paulo epidemiologic sleep study. Sleep Med. 2010; 11(5):441-6

Xu Y, Zhao S, Shi J, Wang Y, Shi B, Zheng Q, et al. 3-dimensional computed tomographic analysis of the pharynx in adult patients with unrepaired isolated cleft palate. Journal of oral and maxillofacial surgery : official journal of the American Association of Oral and Maxillofacial Surgeons. 2013;71(8):1424-34.

Zheng ZH, Yamaguchi T, Kurihara A, Li HF, Maki K. Three-dimensional evaluation of upper airway in patients with different anteroposterior skeletal patterns. Orthodontics \& craniofacial research. 2014;17(1):38-48. 

Anexos 

ANEXO 1 - Aprovação pelo Comitê de Ética em Pesquisa do HRAC/USP

HOSPITAL DE REABILITAÇÃO
DE ANOMALIAS
CRANIOFACIAIS DA USP

\section{PARECER CONSUBSTANCIADO DO CEP}

\section{DADOS DO PROJETO DE PESQUISA}

Título da Pesquisa: ANÁLISE TRIDIMENSIONAL DAS VIAS AÉREAS SUPERIORES DE PACIENTES COM FISSURA LABIOPALATINA E DISCREPÂNCIA MAXILOMANDIBULAR

Pesquisador: Thiago Freire Lima

Área Temática:

Versão: 1

CAAE: 15205413.7 .0000 .5441

Instituição Proponente: Hospital de Reabilitação de Anomalias Craniofaciais da USP

Patrocinador Principal: Financiamento Próprio

\section{DADOS DO PARECER}

Número do Parecer: 440.749

Data da Relatoria: $29 / 10 / 2013$

\section{Apresentação do Projeto:}

Estudo transversal retrospectivo de dissertação no qual os pesquisadores se propõem a avaliar o volume da faringe de indivíduos com e sem fissuras labiopalatinas por meio de tomografias computadorizadas de feixe cônico.

Segundo os autores pouco se sabe sobre o efeito das fissuras sobre a faringe. Telerradiografias em norma lateral de crianças com fissura labiopalatina foram comparadas com as de indivíduos sem fissura e demonstrou-se uma redução das dimensões faríngeas nos pacientes com fissura (Smahel e Müllerová, 1992). Esses autores associaram essa redução ao retroposicionamento da maxila comum nas crianças com fissura levando à uma redução da nasofaringe esquelética e consequentemente do espaço aéreo faríngeo. Controversalmente, Cheung e Oberoi (2012) demonstraram, por meio de estudo volumétrico, utilizando imagens tomográficas de feixe cônico, que a faringe dos pacientes com fissura apresentava dimensões similares à de pacientes sem fissura. Os mesmos resultados foram observados por Aras, Olmez e Dogan (2012), à exceção do volume da cavidade nasal que, na população

estudada, estava significantemente diminuída em relação aos pacientes sem fissura. Os pesquisadores atuais alegam que em nenhum dos estudos supracitados houve um controle do padrão facial esquelético estudado. Isto significa que, em uma mesma amostra, aqueles autores

\begin{tabular}{|c|c|c|c|c|c|}
\hline \multicolumn{6}{|c|}{ Endereço: SILVIO MARCHIONE 3-20 } \\
\hline Bairro: & VILA NOVA CIDADE U & IVERSITA & ARIA & $17.012-900$ & \\
\hline UF: SP & Município: & BAURU & & & \\
\hline Telefone & (14) $3235-8421$ & Fax: & (14)3234-7818 & E-mail: & uep_projeto@centrinho.usp.br \\
\hline
\end{tabular}




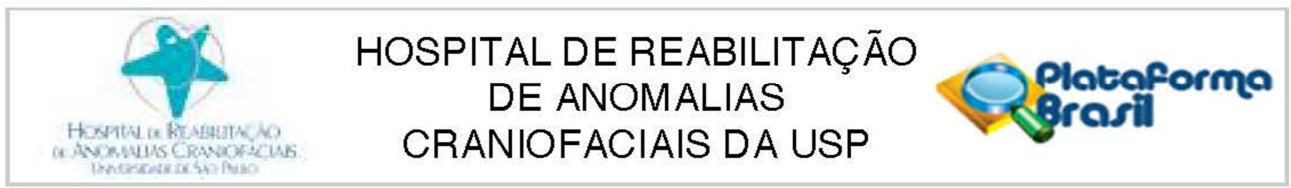

Continuaçăo do Parecer: 440.749

podem ter avaliado pacientes classe I de Angle, que apresentam uma relação maxilomandibular normal ou pacientes classe II ou III, que apresentam reconhecidamente uma redução do espaço aéreo posterior inerente à discrepância maxilomandibular (Claudino et al., 2013). Dessa maneira, na pesquisa atual pretende-se avaliar tomografias computadorizadas de feixe cônico de pessoas com e sem fissuras labiopalatinas que possuem o padrão classe III de Angle.

\section{Objetivo da Pesquisa:}

Avaliar retrospectivamente por meio de tomografia computadorizada o volume do espaço aéreo do paciente com fissura labiopalatina e discrepância maxilomandibular e compará-los com pacientes sem fissura e com discrepância maxilomandibular.

\section{Avaliação dos Riscos e Benefícios:}

Por ser um estudo transversal retrospectivo, que utilizará tomografias de banco de dados, não existem riscos associados ao estudo em questão.

Com este estudo os autores pretendem caracterizar as possíveis alterações existentes nas vias aéreas superiores do paciente com fissura e com discrepância maxilomandibular, estabelecendo uma correlação positiva entre a via aérea estreita e a presença da fissura per se. Desta forma, a partir dos dados obtidos, será possível evidenciar, em estudo futuro, o impacto positivo da cirurgia ortognática para correção das discrepâncias maxilomandibulares sobre a via aérea destes pacientes.

\section{Comentários e Considerações sobre a Pesquisa:}

A pesquisa está bem estruturada e tem mérito científico.O estudo utilizará tomografias computadorizadas de feixe cônico de pessoas com fissuras labiopalatinas do arquivo da Seção de Diagnóstico Bucal do HRACUSP, que serão consideradas o grupo de estudo e tomografias computadorizadas de feixe cônico de pessoas sem fissuras labiopalatinas do arquivo de uma clínica privada de Bauru, as quais serão o grupo controle. Somente tomografias de pessoas com padrão esquelético classe III serão incluídas em ambos os grupos.

As tomografias que serão avaliadas deverão ter sido obtidas pelo protocolo: FOV $16 \times 13 \mathrm{~cm}$, tempo de exposição de 26,9 segundos, $120 \mathrm{kV}, 37,07 \mathrm{~mA}$ e resolução de 0,25 voxels. Essas imagens serão visualizadas no programa Dolphin Imaging 11.0 de análise de imagens por um mesmo avaliador em dois momentos distintos, com intervalo de 1 mês entre as medidas. Serão considerados os valores médios de área e volume obtidos nas duas medições.

Os dados obtidos serão comparados entre si, a significância das diferenças entre as amostras será

Endereç: SILVIO MARCHIONE 3-20

Bairro: VILA NOVA CIDADE UNIVERSITARIA CEP: $17.012-900$

UF: SP Município: BAURU

Telefone: (14)3235-8421 Fax: (14)3234-7818 E-mail: uep_projeto@centrinho.usp.br 


\section{HOSPITAL DE REABILITAÇÃO DE ANOMALIAS CRANIOFACIAIS DA USP}

Continuaçăo do Parecer: 440.749

avaliada por teste "t" de Student para amostras independentes.

Considerações sobre os Termos de apresentação obrigatória:

Os pesquisadores anexaram todos os termos e ressaltaram que caso haja interesse de publicação das imagens os pacientes serão solicitados a assinar o formulário de permissão para o uso de registros para fins científicos.

Recomendações:

Não se aplica.

Conclusões ou Pendências e Lista de Inadequações:

Sugiro a aprovação do projeto de pesquisa.

Situação do Parecer:

Aprovado

Necessita Apreciação da CONEP:

Não

Considerações Finais a critério do CEP:

O Colegiado acatou o parecer do relator em seus aspectos éticos e metodológicos de acordo com as Diretrizes estabelecidas na Resolução 466/12 e complementares do Conselho Nacional de Saúde. Ressaltamos que, conforme a Resolução CNS 466/12, o pesquisador é responsável por "desenvolver o projeto conforme delineado" e por informar ao CEP as emendas, ou seja, "todos os fatos relevantes que alterem o curso normal dos estudos por ele aprovados e, especificamente, nas pesquisas na área da saúde, dos efeitos adversos e da superioridade significativa de uma intervenção sobre outra ou outras comparativas" (alterações que envolva métodos, critérios éticos, mudança de pesquisadores/entrevistadores e instrumental), tais emendas devem ser entregues na Seção de Apoio a Pesquisa do SVAPEPE, bem como anexadas na Plataforma Brasil. O CEP avaliará e emitirá o parecer das emendas.

O pesquisador também fica responsável pela entrega dos relatórios semestrais e final, bem como notificalos pela Plataforma Brasil.

Informamos que após o recebimento do trabalho concluído, este Comitê enviará o parecer final para publicação do trabalho.

Endereço: SILVIO MARCHIONE 3-20

Bairro: VILA NOVA CIDADE UNIVERSITARIA CEP: $17.012-900$

UF: SP Município: BAURU

Telefone: (14)3235-8421 Fax: (14)3234-7818 E-mail: uep_projeto@centrinho.usp.br 


HOSPITAL DE REABILITAÇÃO
DE ANOMALIAS
CRANIOFACIAIS DA USP

Continuaçăo do Parecer: 440.749

BAURU, 30 de Outubro de 2013

Assinador por:

Marcia Ribeiro Gomide

(Coordenador)

Endereço: SILVIO MARCHIONE 3-20

Bairro: VILA NOVA CIDADE UNIVERSITARIA CEP: $17.012-900$

UF: SP Município: BAURU

Telefone: (14)3235-8421 Fax: (14)3234-7818 E-mail: uep_projeto@centrinho.usp.br 
ANEXO 2 - Termo de Compromisso de Manuseio de Informações

Nós, Thiago Freire Lima e Ivy Kiemle Trindade Suedam, abaixo assinados, pesquisadores envolvidos no projeto de título: ANÁLISE TRIDIMENSIONAL DAS VIAS AÉREAS SUPERIORES DE PACIENTES COM FISSURA LABIOPALATINA E DISCREPÂNCIA MAXILOMANDIBULAR nOS comprometemos a manter a confidencialidade sobre os dados coletados nos arquivos do HRAC/USP, bem como a privacidade de seus conteúdos, como preconizam os Documentos Internacionais e a Res. 196/96 do Ministério da Saúde, parágrafo III "Aspectos Éticos Envolvendo Seres Humanos".

Informo que os dados a serem coletados dizem respeito a tomografias de pacientes com fissura labiopalatina e discrepância maxilomandibular, obtidas previamente à cirurgia ortognática, para fins de planejamento cirúrgico, ocorridos entre as os anos de 2008 a 2013. Após conclusão do estudo, uma cópia de todos os materiais e/o dados coletados (fotografias, radiografias, tomografias e respectivos laudos odontológicos e médicos, vídeo imagens, amostra de voz, registros clínicos) obtidos na pesquisa deverão ser encaminhados ao Centro de Pesquisa Clínica, para arquivamento.

Bauru, 10 de setembro de 2013.

Nome

R.G.

Assinatura

Thiago Freire Lima

45962108-7

Ivy Kiemle Trindade Suedam

Responsável técnico do Departamento, Divisão, Serviço e Seção

Referência: www.pucpr.br/arquivosUpload/1237436911258120019.doc 